\title{
Article \\ Characterization of Porous Scaffolds Fabricated by Joining Stacking Based Laser Micro-Spot Welding (JS-LMSW) for Tissue Engineering Applications
}

\author{
Luis D. Cedeño-Viveros ${ }^{1}$, Ciro A. Rodriguez ${ }^{1,2} \mathbb{D}$, Victor Segura-Ibarra ${ }^{1}$, Elisa Vázquez ${ }^{1,2, *(\mathbb{D})}$ \\ and Erika García-López ${ }^{1,2, *(D)}$ \\ 1 Tecnológico de Monterrey, Escuela de Ingeniería y Ciencias, Ave. Eugenio Garza Sada 2501, Monterrey 64849, \\ Mexico; luis.cedeno@tec.mx (L.D.C.-V.); ciro.rodriguez@tec.mx (C.A.R.); victor.segura@tec.mx (V.S.-I.) \\ 2 Laboratorio Nacional de Manufactura Aditiva y Digital (MADiT), Apodaca 66629, Mexico \\ * Correspondence: elisa.vazquez@tec.mx (E.V.); garcia.erika@tec.mx (E.G.-L.)
}

check for

updates

Citation: Cedeño-Viveros, L.D.; Rodriguez, C.A.; Segura-Ibarra, V.; Vázquez, E.; García-López, E. Characterization of Porous Scaffolds Fabricated by Joining Stacking Based Laser Micro-Spot Welding (JS-LMSW) for Tissue Engineering Applications. Materials 2022, 15, 99. https:// doi.org/10.3390/ma15010099 Academic Editor: Francesco Baino

Received: 5 November 2021 Accepted: 18 December 2021 Published: 23 December 2021

Publisher's Note: MDPI stays neutral with regard to jurisdictional claims in published maps and institutional affiliations.

Copyright: (c) 2021 by the authors. Licensee MDPI, Basel, Switzerland. This article is an open access article distributed under the terms and conditions of the Creative Commons Attribution (CC BY) license (https:// creativecommons.org/licenses/by/ $4.0 /)$.

\begin{abstract}
A novel manufacturing approach was used to fabricate metallic scaffolds. A calibration of the laser cutting process was performed using the kerf width compensation in the calculations of the tool trajectory. Welding defects were studied through X-ray microtomography. Penetration depth and width resulted in relative errors of $9.4 \%, 1.0 \%$, respectively. Microhardness was also measured, and the microstructure was studied in the base material. The microhardness values obtained were $400 \mathrm{HV}, 237 \mathrm{HV}$, and $215 \mathrm{HV}$ for the base material, HAZ, and fusion zone, respectively. No significant difference was found between the microhardness measurement along with different height positions of the scaffold. The scaffolds' dimensions and porosity were measured, their internal architecture was observed with micro-computed tomography. The results indicated that geometries with dimensions under $500 \mu \mathrm{m}$ with different shapes resulted in relative errors of $\sim 2.7 \%$. The fabricated scaffolds presented an average compressive modulus $\sim 13.15 \mathrm{GPa}$, which is close to cortical bone properties. The proposed methodology showed a promising future in bone tissue engineering applications.
\end{abstract}

Keywords: JS-LMSW; laser micro-spot welding; laser micro-cutting; sheet lamination; additive manufacturing; bone scaffolds

\section{Introduction}

Osteoporosis, trauma caused by fracture, debridement procedures done in bone infections, and resection of bone tumors are the main causes of human bone damage [1]. Despite bone tissue having a remarkable capacity to repair and heal itself after trauma and illness, critical-sized and large bone defects represent a challenge in today's clinical practice due to bone repair which is limited by their dimension [1,2]. Bone tissue engineering provides a way to repair critical-sized defects by providing a three-dimensional structure called a scaffold $[2,3]$. Today, stainless steel and titanium alloys are the most common materials used in orthopedics load-bearing implants due to their good biocompatibility and their mechanical properties close to the natural bone or even higher [4]. For example, AISI302 stainless steel alloy has been reported as the first metallic alloy to fabricate orthopedic implants [5]. Some applications of AISI302 stainless steel are dental brackets [6] and orthodontic wires [7,8]. However, the AISI302 alloy is characterized by its good biocompatibility in the stomatognathic system's tissues and its ability to achieve a wide range of mechanical properties by cold working and annealing with low manufacturing costs [9]. It has been replaced by AISI316L alloy due to its high corrosion resistance, which has allowed its application in bone plates, screws, and oral implants [6]. To the author's best knowledge, there is only a study conducted by Cedeño-Viveros et al. [10] using AISI302 alloy in a sheet lamination process for potential applications of bone tissue engineering scaffolds.

Additive manufacturing (AM) has revolutionized the fabrication of complex structures for bone tissue engineering applications [11]. AM methods have the ability to customize 
the global shape and the internal architecture of the scaffold [4]. Laser powder bed fusion processes (LPBF) are commonly used for the fabrication of metallic bone scaffolds $[4,11]$. However, they have some typical disadvantages related to their high cost of implementation; they require extensive training, occupy large spaces, and are unable to produce high volumes [4,11]. A few works have been found in the literature regarding AISI316L scaffolds manufactured by AM (Table 1). These have reported a mechanical behavior similar to human cortical or cancellous bone mechanical properties. According to Hing et al. [12], there are several differences between cortical and cancellous bone in its stiffness, strength, and toughness. For example, cortical bone has a consistent density compared with cancellous bone, whose mechanical properties are dependent on its porosity and architecture.

Table 1. AISI316L bone scaffolds mechanical properties found in the literature.

\begin{tabular}{ccccc}
\hline Ref. & Process & $\begin{array}{c}\text { Compressive } \\
\text { Modulus } \\
\mathbf{( G P a )}\end{array}$ & $\begin{array}{c}\text { Compressive } \\
\text { Strength } \\
\mathbf{( M P a )}\end{array}$ & $\begin{array}{c}\text { Measured } \\
\text { Porosity } \\
\mathbf{( \% )}\end{array}$ \\
\hline$[13]$ & SLS & $26-43 \mathrm{GPa}$ & $20-32$ & $50-46$ \\
{$[14]$} & SLS & $1.58-6.64 \mathrm{GPa}$ & $15.5-52.8$ & $58-28$ \\
{$[15]$} & SLM & $0.15 \mathrm{GPa}$ & 3 & 87 \\
{$[16]$} & Binder Jetting & $0.26-3.06 \mathrm{GPa}$ & $6.3-545.5$ & $50-27$ \\
\hline
\end{tabular}

Dewidar et al. [13] fabricated austenitic AISI 316L stainless steel scaffolds with a 50\% porosity and with elastic modulus and compression strength close to the human cortical bone through the selective laser sintering process (SLS). Xie et al. [14] fabricated metal knee joints from coated stainless steel powder (i.e., 316L coated with ethylene-vinyl acetate resin) using the SLS process and obtaining parts with controlled porosity that can match the human cancellous bone properties. Capek et al. [15] explored the mechanical properties of austenitic AISI316L stainless steel for producing highly porous scaffolds through selective laser melting (SLM) with mechanical properties close to the cancellous bone features. Vangapally et al. [16] studied different lattice designs with circular and square $2 \mathrm{~mm}$ pores and manufactured by binder jet additive manufacturing in AISI316 stainless steel for bone scaffolds applications.

In order to accomplish the scaffold design requirements, an evenly distributed pore and a highly controlled size promotes bone tissue ingrowth and facilitates the imitation of bone mechanical properties $[17,18]$. In this context, dimensional accuracy plays an important role in achieving the desired pore size with high morphological repeatability (i.e., shape, size, and distribution). In metal AM, small pore sizes have high difficulty in fabricating satisfactory samples of fine definition [11]. According to Garot et al. [4], the dimensional accuracies are $\pm 300 \mu \mathrm{m}$ and $\pm 100 \mu \mathrm{m}$ for LPBF.

Sheet lamination is an AM process that involves the joining and shaping of sheet feedstock [19]. In the last decades, sheet lamination techniques have been implemented to produce micro molds, micro-gears, and micro-electrodes for the electronic industry [20-22]. For example, $\mathrm{Xu}$ et al. [23] fabricated stainless steel (Cr18Ni9) micro mold cavities of $250 \mu \mathrm{m}$ $\times 250 \mu \mathrm{m} \times 50 \mu \mathrm{m}$ using a sheet lamination, which consisted in the laser cutting of metallic foils of $10 \mu \mathrm{m}$ of thickness that were joined by micro-electric slip welding. The results showed horizontal and vertical size errors of $0.5 \mu \mathrm{m}$ and $2 \mu \mathrm{m}$, respectively. Additionally, $\mathrm{Xu}$ et al. [20] fabricated $\mathrm{Cu}$ micro-electrodes with dimensional errors between $8.8 \mu \mathrm{m}$ and $16.4 \mu \mathrm{m}$ by cutting $\mathrm{Cu}$ foils of $100 \mu \mathrm{m}$ of thickness using wire electrical discharge machining and joining them by vacuum pressure thermal diffusion welding.

Laser micro-cutting has demonstrated great potential to fabricate one of the most demanding medical devices, coronary stents, with high accuracy and high-quality surface finish [24]. Laser micro-welding is able to join all types of metallic materials and produce joints with high strengths, which are consistent with those of the base material [25]. Advantages of the laser micro-welding process are high precision due to the small size of 
the laser spot, non-contact to prevent contamination, and excellent weld quality with low heat input [26]. Applications of laser micro-welding include intraocular lenses, knee joint replacements, cochlear implants, and pacemakers [27,28]. Cedeño-Viveros et al. [10] studied sheet lamination using laser micro-cutting and laser micro-welding for bone scaffold applications with promising results. This investigation presents the study of bone tissue scaffolds fabricated through Joining Stacking based Laser Micro-Spot Welding (JS-LMSW) as a sheet lamination (additive manufacturing) process. Our methodology is based on the laser micro-cutting of AISI302 sheets, which are joined by laser micro-spot welds. In this paper, we present a calibration procedure implemented in the laser micro-cutting process to improve the dimensional accuracy of micro-shapes of the AISI302 scaffolds. Additionally, the mechanical behavior of the AISI 302 scaffolds fabricated by the proposed methodology was studied and compared with bone mechanical properties.

\section{Materials and Methods}

AISI302 (C0.05 Cr17.5 Ni8.1 Mn0.87 P0.003 S0.002 Si0.25 Mo0.19 wt\%) sheets with $254 \mu \mathrm{m}$ of thickness were used for experimental tests. The laser micro-cutting and microspot welding experiments were performed using a fiber laser machine (PRECO ST2000, Somerset, WI, USA) with a fiber core diameter of $50 \mu \mathrm{m}$. For the laser micro-cutting process, the focal plane was focused on half of the sheet's thickness, and the standoff distance used was $254 \mu \mathrm{m}$ for a measured spot size of $64 \mu \mathrm{m}$. For the laser micro-spot welding process, the standoff distance used was $14.5 \mathrm{~mm}$ to obtain a spot diameter of $143 \mu \mathrm{m}$ on the top surface of the metallic sheets. The process parameters used for the micro-cutting and micro-spot welding are listed in Table 2.

Table 2. Process parameters for the laser micro-cutting and micro-spot welding operations.

\begin{tabular}{ccc}
\hline & Laser Micro-Cutting & Laser Micro-Spot Welding \\
\hline Average Laser Power, $\mathrm{P}_{\mathrm{AVG}}(\mathrm{W})$ & 170 & 220 \\
Pulse frequency, $\mathrm{f}(\mathrm{Hz})$ & 1100 & - \\
Assist gas pressure, $\mathrm{p}_{1}(\mathrm{psi})$ & 150 & $\approx 0$ \\
Feed rate, $\mathrm{f}(\mathrm{mm} / \mathrm{min})$ & 200 & - \\
Exposure time, $\mathrm{t}(\mathrm{ms})$ & - & 50 \\
Shielding gas pressure, $\mathrm{p}_{\mathrm{X}}(\mathrm{psi})$ & - & $\approx 0$ \\
Shielding gas flux, $\mathrm{f}_{\mathrm{X}}(\mathrm{L} / \mathrm{min})$ & - & 15 \\
\hline
\end{tabular}

\subsection{Laser Micro-Cutting Specimen Calibration}

CAM software (Autodesk Fusion 360, California, USA) was used to obtain the toolpaths trajectories and the G-code to perform the laser cutting operations. Figure 1a,b shows the laser spot trajectory. The tool paths trajectories were calculated: without the kerf width compensation Figure 1a and with the kerf width compensation Figure 1b. Five lines of $10-\mathrm{mm}$ length were laser cut in AISI302 shim with a thickness of $0.250 \mathrm{~mm}$ (Figure 1c). The measurements of the kerf width $(\mathrm{kw})$ were performed in six points along the line on the top side using the Stereomicroscope V8 (Carl Zeiss, Jena, Germany) Figure 1c. These kerf width $(\mathrm{kw})$ measurements were used to calculate the average kerf width to compensate for the tool's trajectory in the laser cut. 


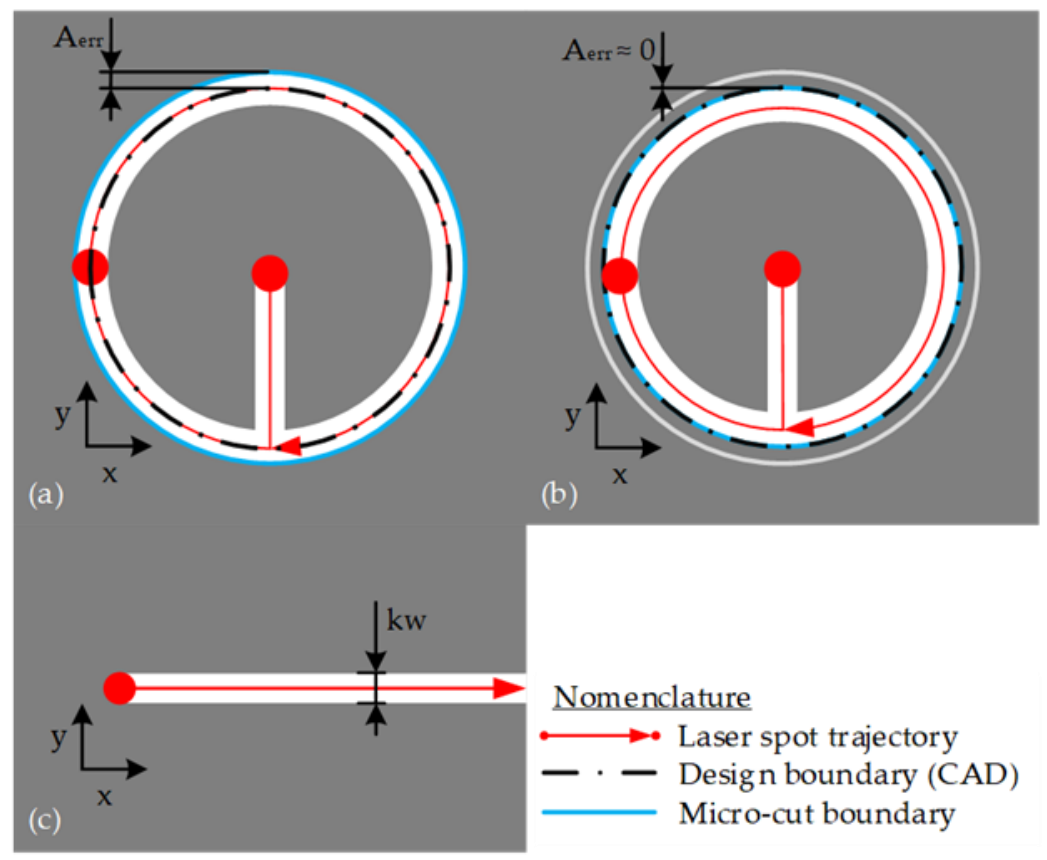

Figure 1. Laser micro-cutting trajectory (a) without kerf width compensation and (b) with kerf width compensation, and (c) kerf width (kw) measurement.

The sample designed to study kerf width compensation was modeled using CAD software (Siemens NX10, Houston, TX, USA). Each sample consisted of an AISI302 sheet of $20 \times 20 \mathrm{~mm}$ to obtain a rectangular array of five rows by four columns of different shapes. Each row consisted of a different length (L) in a range between $250 \mu \mathrm{m}$ and $3000 \mu \mathrm{m}$, while each column had a different shape based on the corner radius (R). The corner radius ( $R$ ) represents a portion of the length (L) (i.e., $0, \mathrm{~L} / 4, \mathrm{~L} / 3, \mathrm{~L} / 2$ ). A graphical view of the sample outline with dimensions is displayed in Figure 2a, and a detailed view of the different shapes of row 1 is displayed in Figure $2 b$. Additionally, Table 3 presents the nominal dimensions: length $(\mathrm{L})$ and corner radius $(\mathrm{R})$ of each row and column from the CAD model. For square and circle shapes, the corner radius $(R)$ and the length dimension $(\mathrm{L})$ were equal to 0 , respectively. Six samples containing all shapes were produced in sheets: three samples were fabricated without the compensation of the kerf width, and three samples were fabricated with the compensation of the kerf width. After fabrication, images of the shapes were obtained using an inverted PMG3 optical microscope (Olympus, Tokyo, Japan). The shapes' length ( $\mathrm{L}$ ) and corner radius (R) were measured in the ImageJ software (National Institute of Health, Maryland, USA). The relative error $\left(\operatorname{err}_{\mathrm{R}}\right)$ was calculated using Equations (1) and (2). Where $L$ and $R$ correspond to the nominal values for the length and corner radius presented in Table $3 . \mathrm{L}_{\mathrm{m}}$ and $\mathrm{R}_{\mathrm{m}}$ are the measured length and corner radius in the fabricated shapes.

$$
\begin{aligned}
& \operatorname{err}_{R}=\frac{\left|L-L_{m}\right|}{L} \times 100 \%, \\
& \operatorname{err}_{R}=\frac{\left|R-R_{m}\right|}{R} \times 100 \%,
\end{aligned}
$$




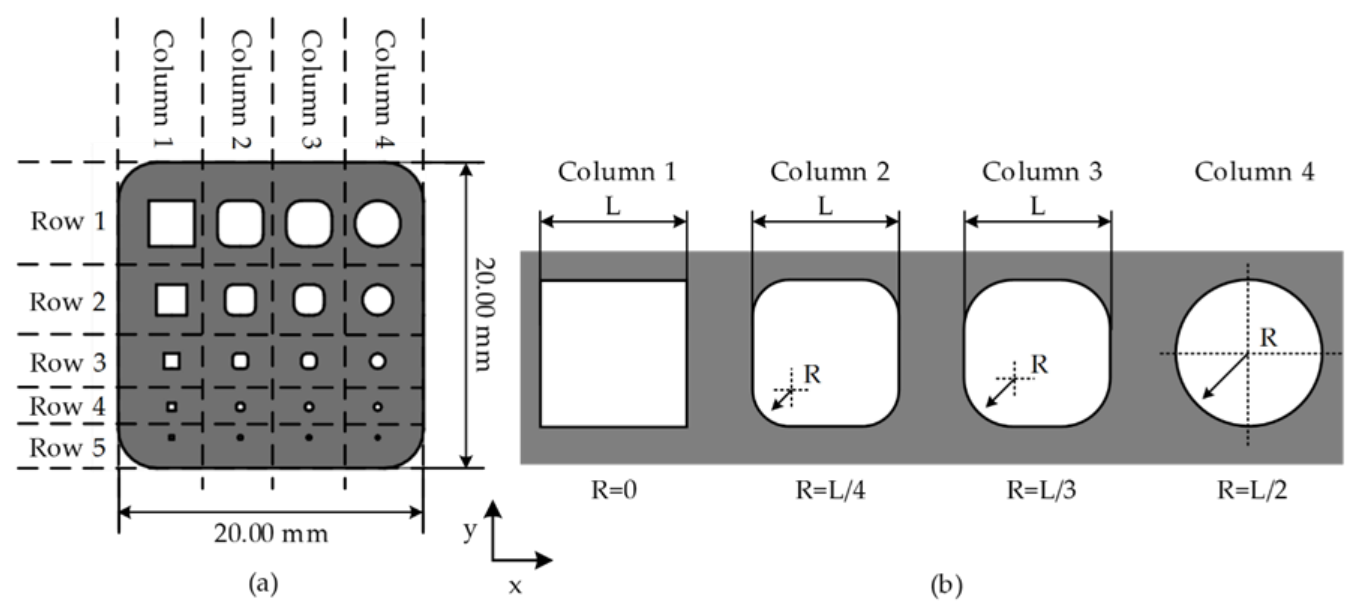

Figure 2. (a) Sample geometry design for laser micro-cutting and (b) row 1 with the design of shapes of each column.

Table 3. Nominal dimensions of each sample for laser micro-cutting calibration.

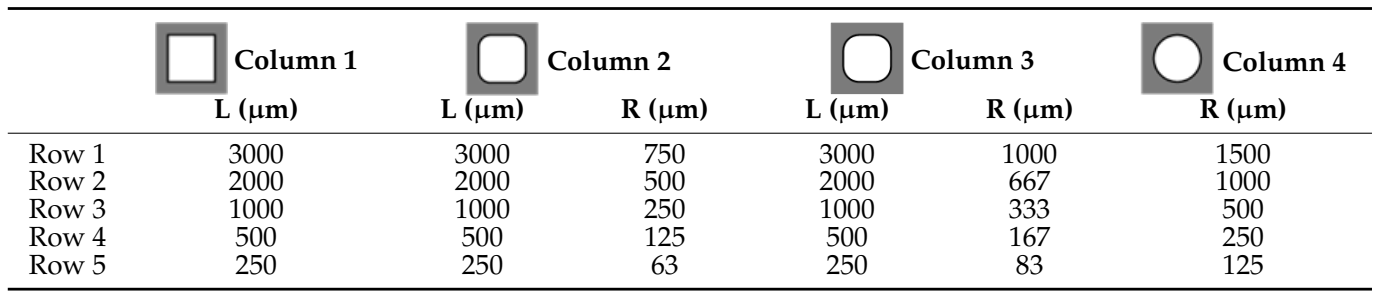

\subsection{Scaffold Manufacture and Characterization}

The proposed scaffold consisted of cutting AISI302 $20 \times 20 \mathrm{~mm}$ sheets with a $0.254-\mathrm{mm}$ thickness. Forty-three sheets were stacked using laser micro-spot welding. The scaffold was joined using the methodology explained in our previous work [10]. The final scaffold was cut from the stack using a wire electrical discharge machining (WEDM) machine. Six cubic scaffolds were created $(10 \times 10 \times 11 \mathrm{~mm})$. Figure 3 presents the scaffold designed with the established dimensions. Figure 3 a shows the stack built after laser cutting and micro-spot welding, Figure 3b illustrates the scaffold after WEDM, and Figure $3 \mathrm{c}$ presents the micro-spot designed to achieve full penetration in accordance with the ISO13919-1 to join three AISI302 sheets and considering the gaps between sheets observed in the previous study [10]. An aspect ratio (d/w) of 1.25 was considered for spot weld designed to assure higher heat transference in the $Z$-axis and minimize mechanical distortions due to heat dissipation losses in the $X$ and $Y$ axes $[29,30]$.

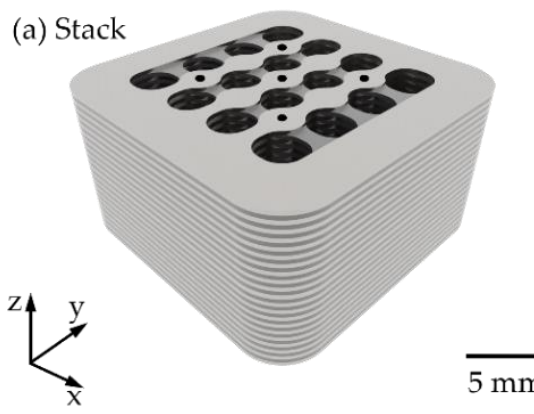

(b) Scaffold

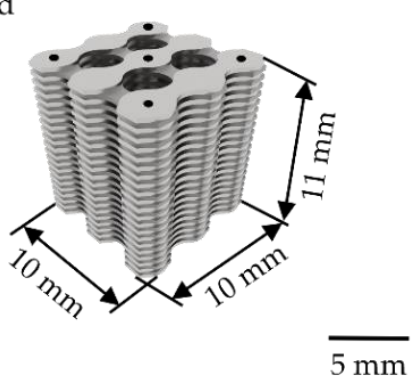

(c)

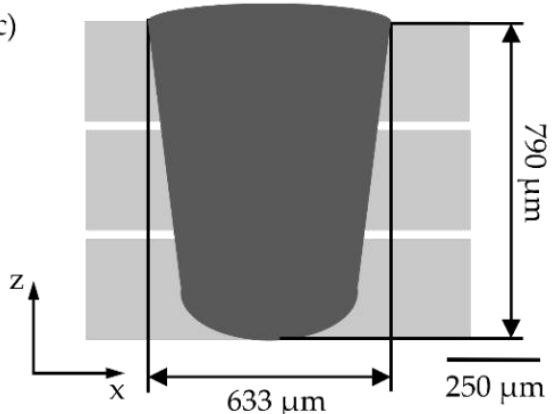

Figure 3. Designed scaffold (a) stack, (b) scaffold, and (c) laser micro-spot weld design.

\subsection{Scaffold Morphological Characterization}

The scaffolds were scanned using micro-computed tomography (ZEISS Metrotom 1500, Jena, Germany) with an accelerating voltage of $125 \mathrm{kV}$ and a beam current of $387 \mu \mathrm{A}$. The 
reconstructed images consisted of $468 \times 372 \times 441$ voxels, with a voxel size of $38.72 \mu \mathrm{m}^{3}$. Several images were captured on the $X Y, Y Z$, and $X Z$ planes. The scaffolds' porosity was determined by the Archimedes' method in accordance with DIN 993-1, DIN 993-2, and DIN 623. The samples were weighed dry and in ethylic alcohol using an analytical scale (Mettler Toledo XPR205,Columbus, OH, USA) based on the methodology reported by Kumar et al. [27]. A scaffold was placed in polyester resin, and the cut was performed with a diamond blade. The sample was chemically attacked with Kallings solution to study the microstructure using an SEM microscope (Zeiss EVOMA25, Jena, Germany). Additionally, the chemical composition was obtained by an EDS analyzer (BRUKER X6/10, Billerica, MA, USA) in two different areas of the microstructure, identifying fusion zone (FZ), heat affected zone (HAZ), and the base material (BM). Additionally, a characterization was performed on the metallography image to identify defects such as pores, shrinkage, root cavities, excessive penetration, and excessive weld metal. These defects were observed in the scaffold cut in the XZ plane (See Figure 3).

\subsection{Scaffold Mechanical Characterization}

Five manufactured scaffolds were tested by compression evaluation in accordance with the ASTM E9 [28]. A universal testing machine (SHIMADZU AG-X, Kyoto, Japan) was used for the tests. The compression tests were performed with a constant crosshead speed of $1 \mathrm{~mm} / \mathrm{min}$ with a $300 \mathrm{kN}$ of load capacity at room temperature. The compressive modulus and compressive yield strength were calculated from the stress-strain curves. Images of the fractured samples were obtained with an SEM microscope (Zeiss EVOMA25, Jena, Germany) for failure analysis after compression tests.

The Vickers's microhardness tests were executed according to the ASTM E384-17 [29] using a hardness testing machine (Zwick/Roell ZHV $\mu-S$, Ulm, Germany). A Class B Vickers indenter certified (Euro Products Calibration Laboratory, Brieley Hill, England) in accordance with the ASTM E92-17. The indenter has a junction line size $\leq 0.05 \mathrm{~mm}$ and face angles of $136.03^{\circ}$ and $135.88^{\circ}$.

The indentations were carried with a weight force of $25 \mathrm{~g}-\mathrm{F}$ and the indentation time was $10 \mathrm{~s}$, per point. Two evaluations of microhardness tests were performed. The first test was conducted in one micro spot weld. Microhardness was measured in a matrix of $11 \times 3$ points across the micro spot weld with a step distance of $0.254 \times 0.125 \mathrm{~mm}$ between points (XZ-plane). In the second test, one scaffold was measured for microhardness in four micro-spot welds along the Z-axis of the scaffold. At each micro-spot, weld six indentations were executed: two in the base material (BM), two in the heat-affected zone (HAZ), and two in the fusion zone (FZ).

\section{Results}

\subsection{Laser Micro-Cutting Specimen Calibration}

Figure 4 shows the relative error of length (Figure $4 a$ ), radius (Figure $4 b$ ), and corner radius of rounded squares (Figure $4 \mathrm{c}, \mathrm{d}$ ). In all figures, the relative error is significantly ( $p$-value $\leq 0.0001)$ smaller when the kerf compensation is used. The dimensional analysis shows that the smallest feature (i.e., lower than $500 \mu \mathrm{m}$ ) increases the relative error considerably. Additionally, micro shapes (i.e., lower than $500 \mu \mathrm{m}$ ) with a kerf width compensation obtained a maximum relative error of $2.7 \%$ compared with non-compensated samples (i.e., the maximum relative error of 19.6\%). While for macro shapes (i.e., higher than $500 \mu \mathrm{m}$ ), the maximum relative errors reported are $4.1 \%$ and $1.4 \%$ for non-compensated and compensated samples, respectively. This suggests that kerf width compensation improves dimensional accuracy when a cutting path is calculated. 

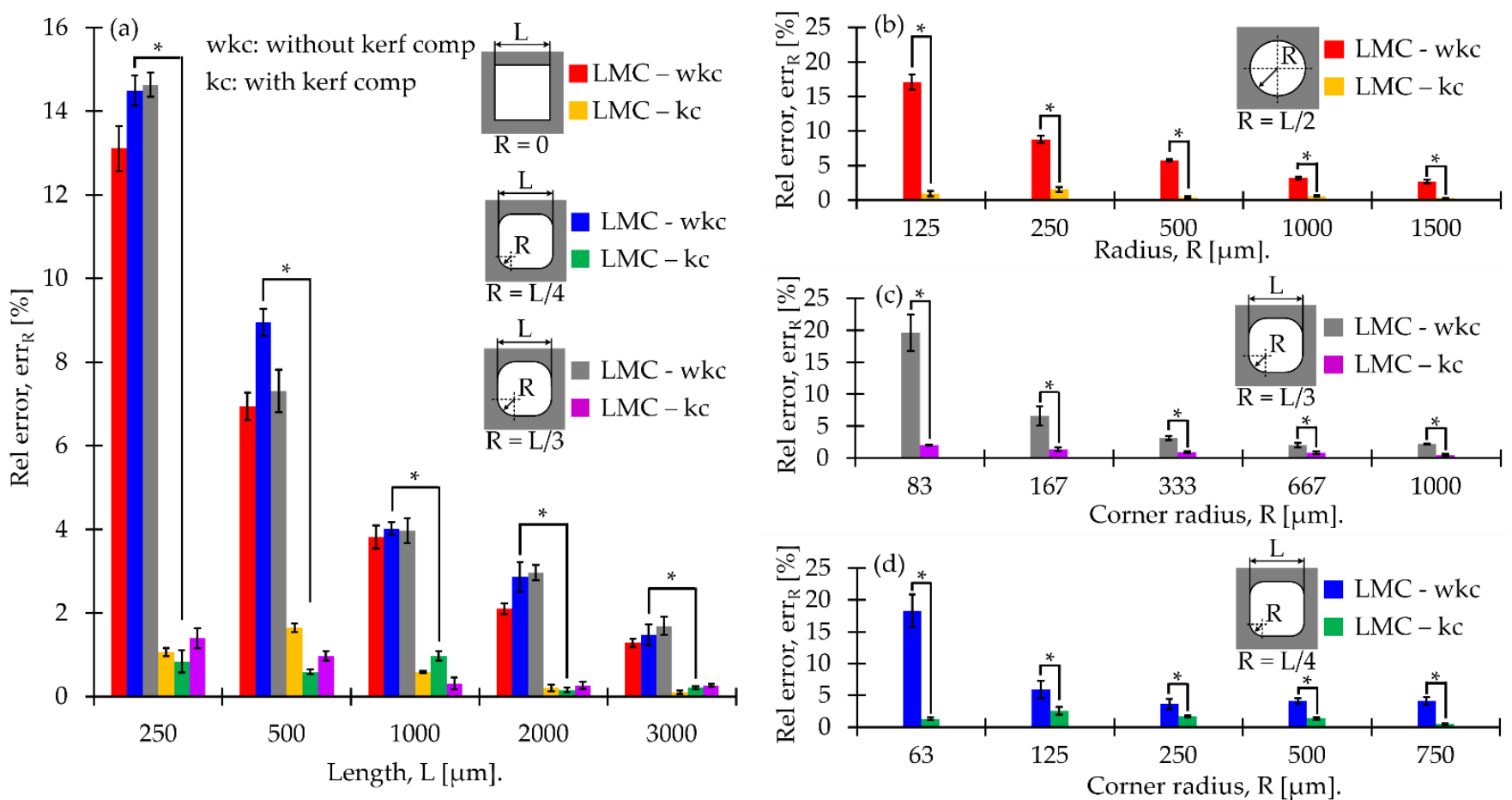

Figure 4. Relative error results from measured: (a) length (L) in pores with $\mathrm{R}=0, \mathrm{~L} / 4, \mathrm{~L} / 3$ and corner radius (c) in pores with (b) $\mathrm{R}=\mathrm{L} / 4$, (c) $\mathrm{R}=\mathrm{L} / 3$, and (d) $\mathrm{R}=\mathrm{L} / 2$. Note: (wkc: without kerf compensation, kc: with kerf compensation, ${ }^{*} p$ value $\left.\leq 0.0001\right)$.

Figure $5 \mathrm{a}-\mathrm{h}$ shows images obtained from laser cutting experiments with a length of $3000 \mu \mathrm{m}$ without kerf compensation Figure $5 \mathrm{a}-\mathrm{d}$ and with kerf compensation Figure $5 \mathrm{e}-\mathrm{h}$. Figure $5 i-p$ presents the results of micro shapes with a length of $250 \mu \mathrm{m}$ without kerf compensation Figure 5i-l and with kerf compensation Figure $5 \mathrm{~m}-\mathrm{p}$. The yellow line indicates the shape profile designed using CAD software.

There is a greater difference between the yellow line and the manufactured shape when the length of the sample is $250 \mu \mathrm{m}$ (Figure $5 \mathrm{i}-1$ ) compared to $3000 \mu \mathrm{m}$ of length (Figure $5 \mathrm{a}-\mathrm{d}$ ) when samples are non-compensated, which is related to the relative errors obtained before. Additionally, slag formation can be seen in $250 \mu \mathrm{m}$ length non-compensated samples (Figure $5 \mathrm{i}-1$ ). For micro shapes with a corner radius equal to $0, \mathrm{~L} / 4$, and $\mathrm{L} / 3$, the formation of dross (Figure $5 \mathrm{~m}-\mathrm{o}$ ) and slag (Figure 5m,p) was observed.

\subsection{Scaffold Morphological Characterization}

Microtomography images are shown in Figure 6. Black holes can be observed in Figure 6 (red oval) that indicate the presence of shrinkages. These shrinkages can also be identified in Figure $6 \mathrm{a}, \mathrm{b}, \mathrm{d}, \mathrm{e}, \mathrm{g}, \mathrm{h}, \mathrm{j}, \mathrm{k}, \mathrm{n}$. No other defects were observed in the microtomography. Figure $6 \mathrm{~b}, \mathrm{e}, \mathrm{k}, \mathrm{h}, \mathrm{n}$ shows micro-welding spots stacked in three columns, which suggests high repeatability in the position of the micro-welding spots. Figure $6 \mathrm{c}, \mathrm{f}, \mathrm{i}, \mathrm{l}, \mathrm{o}$ exhibit the scaffold reconstruction through X-ray tomography in isometric view. There is a high consistency of the final shape of the fabricated scaffolds. Figure 7a shows a scaffold manufactured. The scaffold's final dimensions were $9.622 \pm 0.013 \mathrm{~mm}$ in length and width, with a height of $11.564 \pm 0.008 \mathrm{~mm}$. The dimensional differences compared with design dimensions in the $\mathrm{X}$ and $\mathrm{Y}$ axis are attributed to the WEDM. The scaffolds resulted in a measured porosity of $46.5 \pm 0.5 \%$ calculated by the Archimedes method, which is close to the designed porosity of $47 \%$ calculated by CAD software from the proposed design. Figure $7 \mathrm{~b}$ displays the scaffold's metallography used to observe the micro spot welds. 


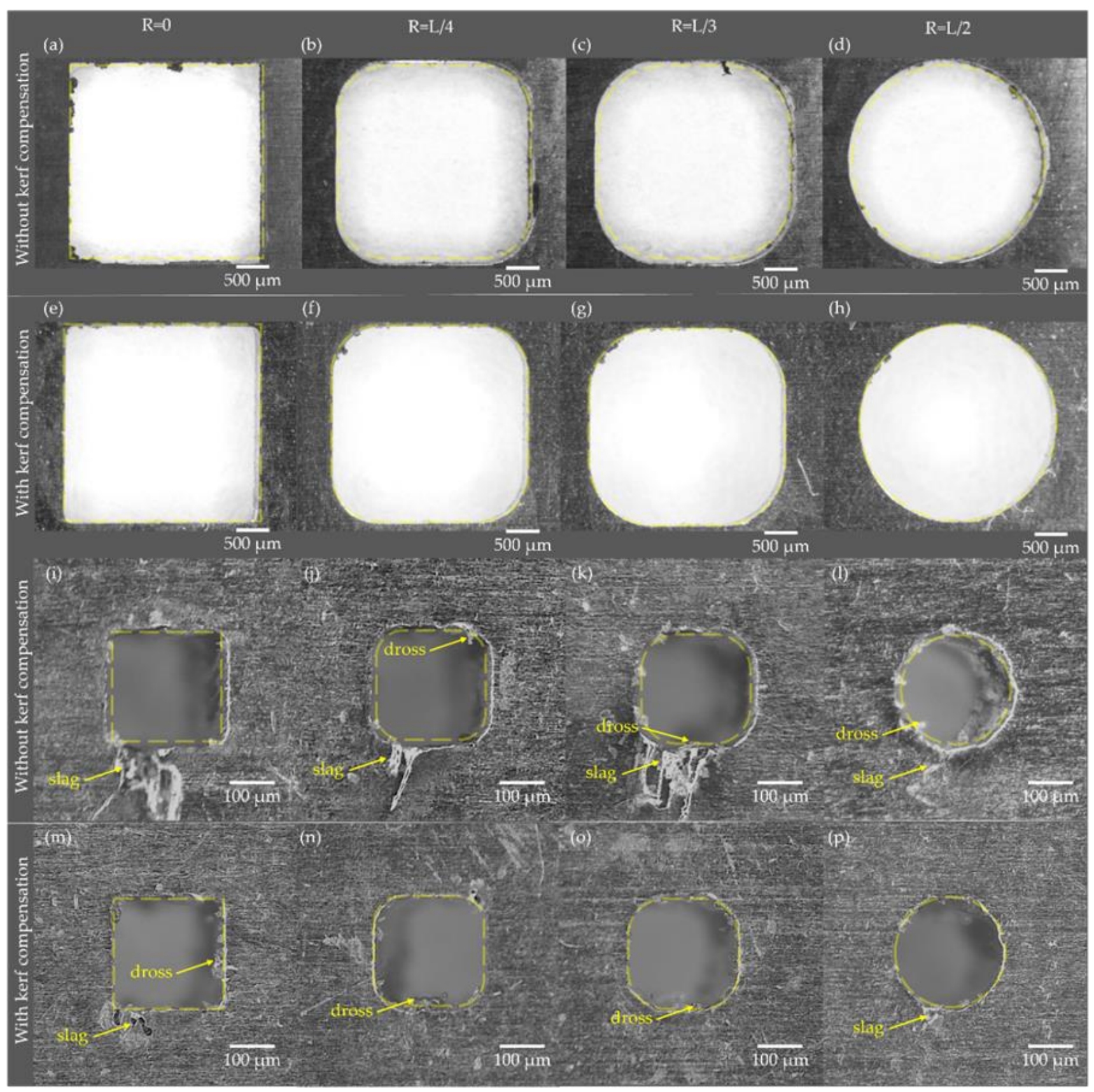

Figure 5. Macro shapes with a length of $3000 \mu \mathrm{m}$ without compensation (a-d) and with compensation $(\mathbf{e}-\mathbf{h})$ and micro shapes corner radius with a length of $250 \mu \mathrm{m}$ without compensation (i-1) and with compensation $(\mathbf{m}-\mathbf{p})$. 


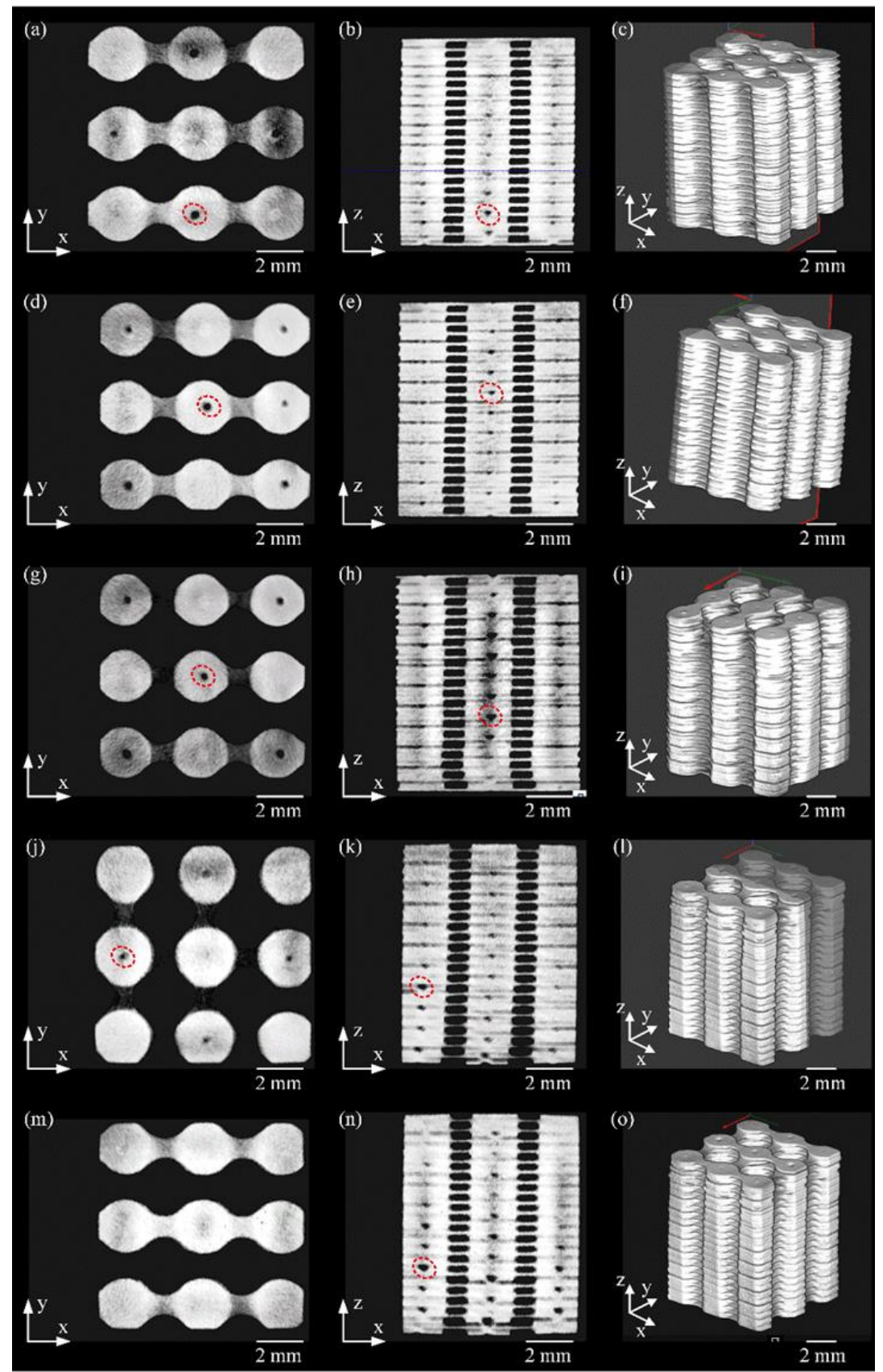

Figure 6. Pictures of the micro-CT analysis. Samples $1-5(\mathbf{a}, \mathbf{d}, \mathbf{g}, \mathbf{j}, \mathbf{m})$ top, $(\mathbf{b}, \mathbf{e}, \mathbf{h}, \mathbf{k}, \mathbf{n})$ lateral, and $(\mathbf{c}, \mathbf{f}, \mathbf{i}, \mathbf{l}, \mathbf{o})$ isometric views.

The results of penetration depth, width, and HAZ width of micro-spot welds are shown in Figure 8. The penetration depth measurements (Figure 8a) decreased from $813 \mu \mathrm{m}$ to values between 704 and $736 \mu \mathrm{m}$ after $2 \mathrm{~mm}$ of the $Z$ scaffold height. While the micro-spot welding width (Figure $8 \mathrm{~b}$ ) increased from $501 \mu \mathrm{m}$ to values between 584 and $616 \mu \mathrm{m}$. HAZ measurements (Figure $8 \mathrm{c}$ ) varied between 25 and $34 \mu \mathrm{m}$. These results demonstrate high repeatability in the micro-spot weld dimensions obtained in this works. Additionally, it is observed that the micro-spot welds under the $\mathrm{Z}$ height of $2 \mathrm{~mm}$ presented a fluted shape which is consistent with our previous study [10]. After the $Z$ height of $2 \mathrm{~mm}$, the micro-spot welds showed a parabolic shape; this change in the weld beads indicated a difference in the heat transfer phenomena $[10,31]$ resulting from the stacking process. 
(a)
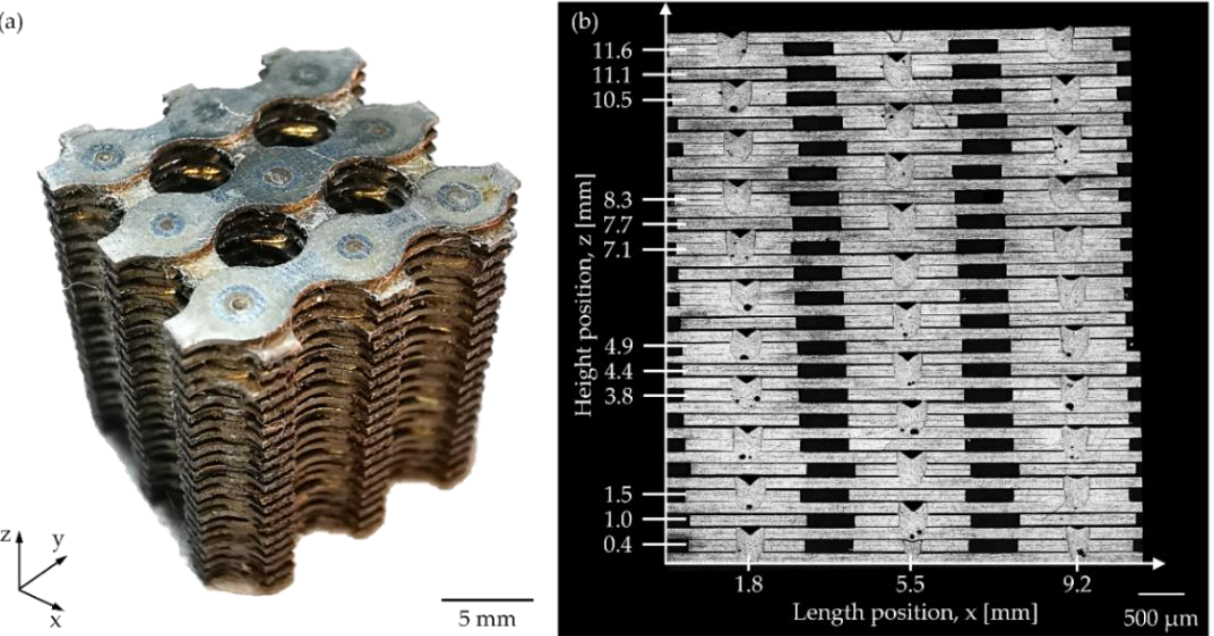

Figure 7. (a) Fabricated scaffold and (b) Metallography of the cross-section of the fabricated scaffold.
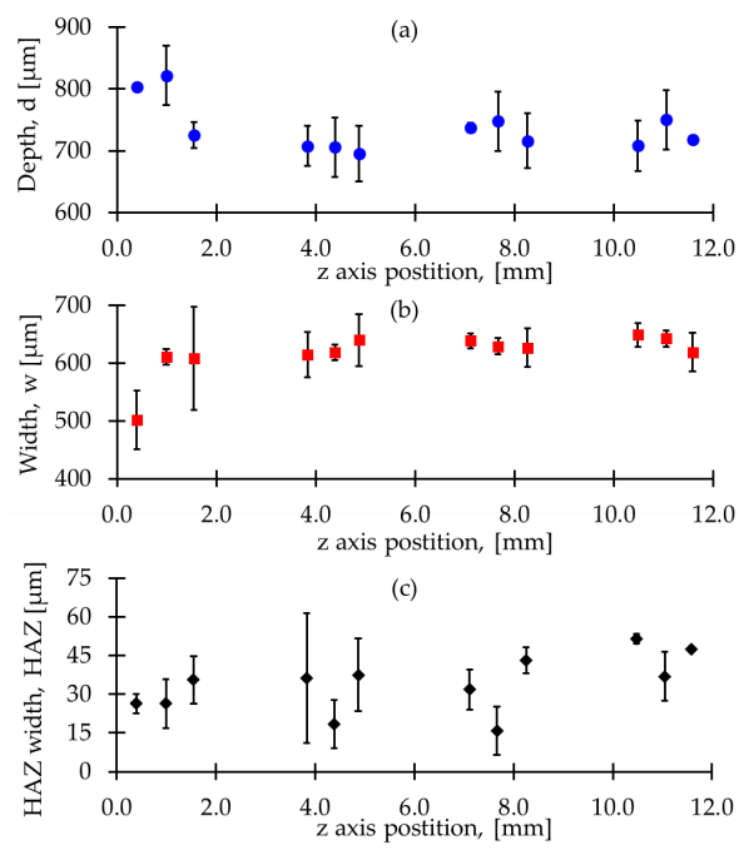

Figure 8. Results for the measured: (a) depth, (b) width, and (c) HAZ width of the micro spot welds.

Welding defects were measured from metallography (Figure $7 \mathrm{~b}$ ). The results were plotted (Figure 9a) to evaluate micro spot quality and the shrinkages evaluation (Figure 9b). A total of 84 pores were found in the metallography section (Figure $7 \mathrm{~b}$ ). Figure 9 presents the pore's size range of 52-75 $\mu \mathrm{m}$; shrinkages in between 95 and $143 \mu \mathrm{m}$; root cavities in a range of $15-32 \mu \mathrm{m}$. Additionally, a single spot exhibited excessive penetration of $\sim 24 \mu \mathrm{m}$. Every spot in the section presented excessive material welded with a size range of 29-37 $\mu \mathrm{m}$. Due to shrinkages found in several micro-spot welds, they were evaluated along the $X$-axis (Figure $9 \mathrm{~b})$. The largest shrinkages were located in the center of the scaffold $(x=5.5 \mathrm{~mm})$ and had an average size of $172 \mu \mathrm{m}$. The shrinkages located in the outer scaffold $(\mathrm{x}=1.8$, $\mathrm{x}=9.2 \mathrm{~mm}$ ) had an average size of $140 \mu \mathrm{m}$ and $80 \mu \mathrm{m}$. The data reported in Figure $9 \mathrm{~b}$ were analyzed using ANOVA (Analysis of Variance); our results indicated that with a confidence level of $95 \%$, the differences between length positions are significant ( $p$-value $=0.0001$ ). 

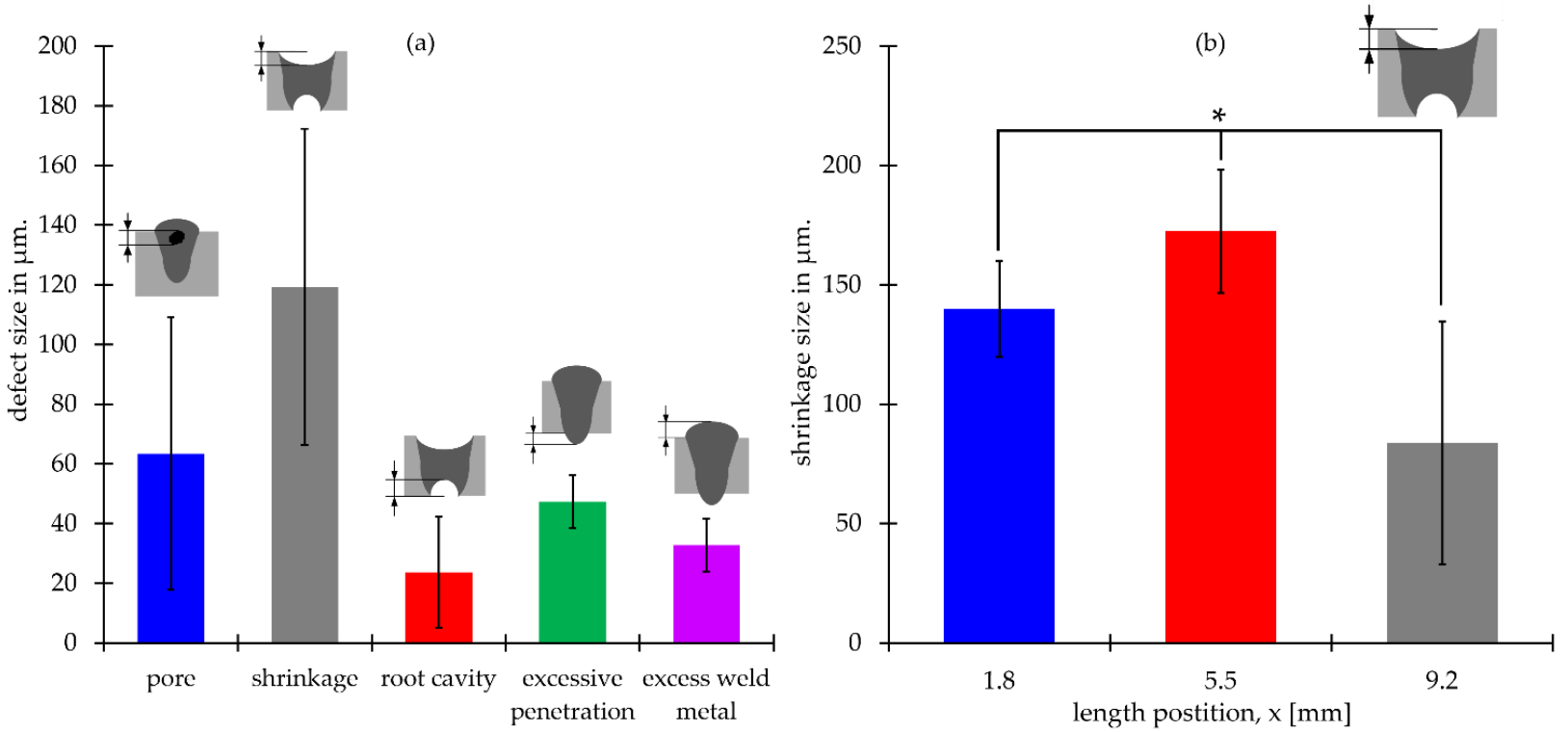

Figure 9. (a) Average size of the defects encountered in the micro-spot welds (b) measurements of the shrinkage defects in the micro-spot welds. ${ }^{*} p$-value $\leq 0.0001$.

Figure 10 presents the SEM micrographs from the fabricated scaffold (Figure 7a). Figure 10a shows dark areas near the HAZ compared with the central area of the spot weld, which indicates the reduction of the ferrite phase $(\delta)$ in the center of the spot weld. Several images were obtained at a different scale to observe the micro spot weld. Figure 10b illustrates the microstructure of two stacked sheets. The upper sheet presented the bottom interface between the fusion zone and the base material. In the fusion zone, epitaxial columnar dendritic growth was found, which is attributed to the solidification process. This columnar growth starts near the HAZ and goes to the central area of the spot weld, and in the base material, elongated and thin grains were present. Additionally, microporosities were found in the base material (Figure 10b). Figure 10c presents FZ, HAZ, and BM. The delimitation of HAZ was observed, and the lower HAZ of the weld was narrow compared with lateral HAZ. This indicates more heat diffusion in the $\mathrm{X}-\mathrm{Y}$ axis than in the Z-axis. Additionally, Figure 10d presents a fusion zone composed of a vermicular ferrite $(\delta)$ phase wrapped in austenite $(\gamma)$. Another identified structure was a lathy ferrite $(\delta)$ core with interdendritic austenite $(\gamma)$ [32].

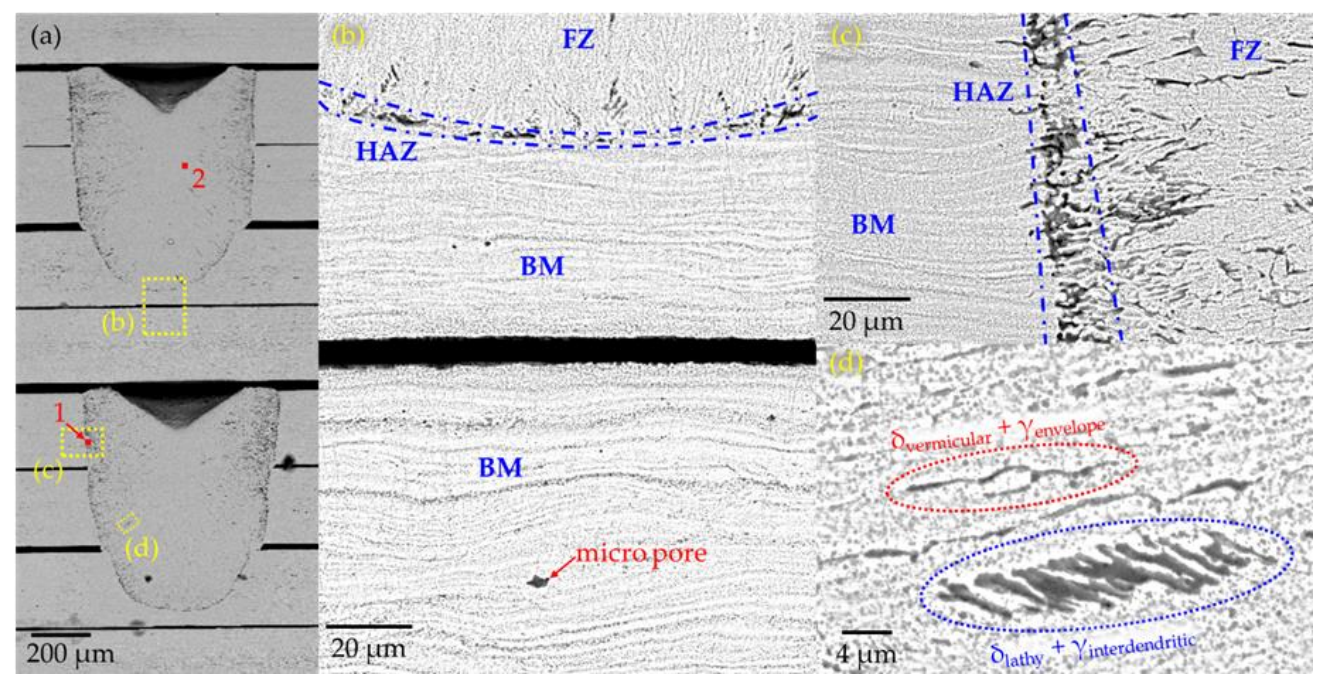

Figure 10. (a) Metallography of two micro spot welding (b) Lowest point of spot welding, (c) Lateral interface between spot welding and raw material (d) microstructure in the fusion zone. 
Figure 11 shows the results of a chemical analysis performed in EDS. Figure 11a,c indicates the HAZ and fusion zone, respectively. A color map of chemical composition (Figure $11 \mathrm{~b}, \mathrm{~d}$ ) was obtained for the same samples. Inside the austenite matrix $(\gamma)$, the presence of precipitates with high $\mathrm{Cr}$ and Ni concentrations (marked in green color (P1) and white (P2)) was identified. The heat-affected zone presented a greater amount of these precipitates (i.e., $22.2 \%$ area) compared to the fusion zone (i.e., $5 \%$ area). Table 4 presents a summary of the phases (i.e., $\delta$ y $\gamma$ ) and precipitates (i.e., P1 y P2).

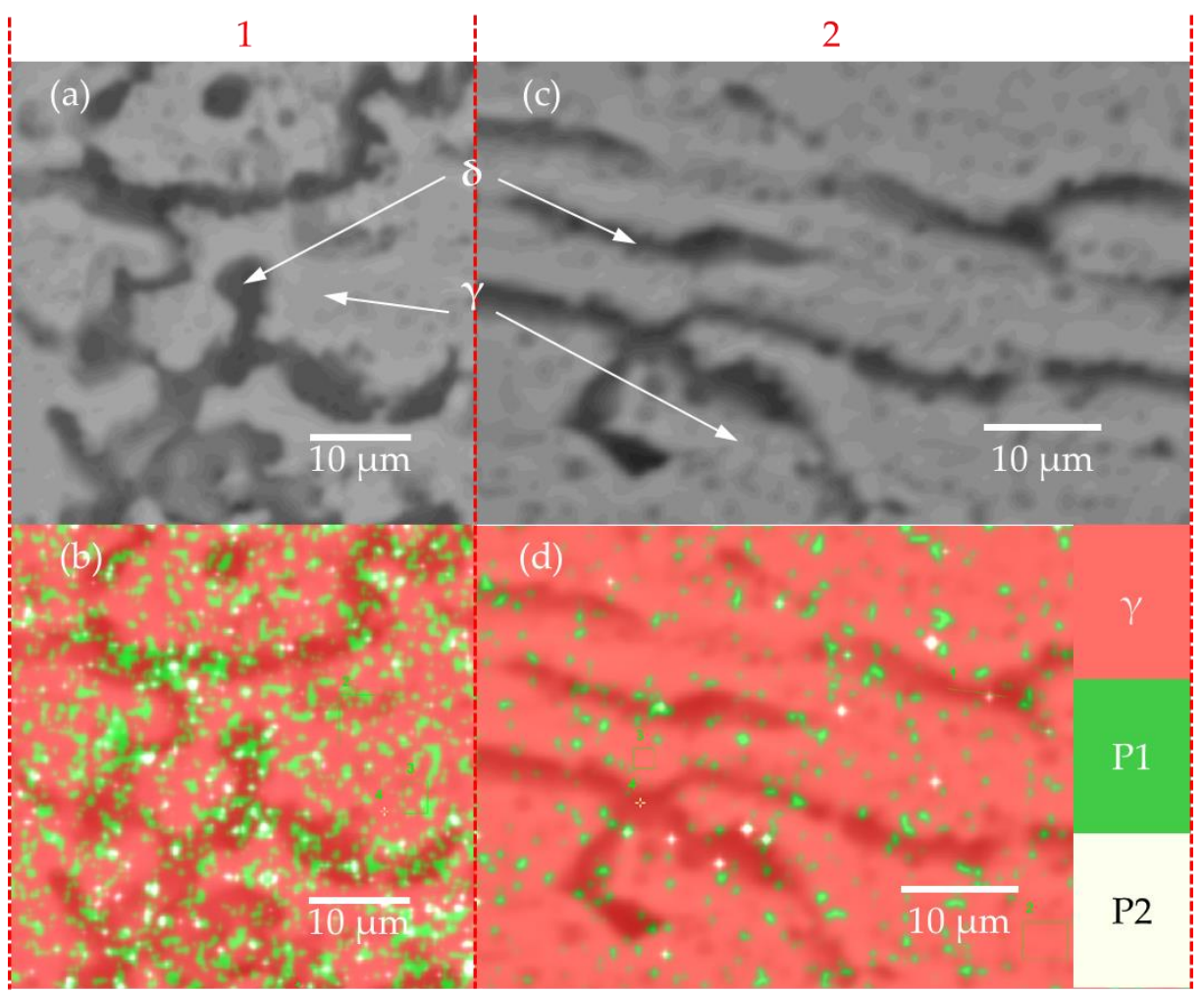

Figure 11. Color mapping in HAZ (1) and fusion zone (2): (a) SEM picture in HAZ (b) EDS mapping in HAZ (c) SEM picture in FZ, and (d) EDS mapping in FZ.

Table 4. Results of the EDS analysis for the phases and precipitates.

\begin{tabular}{cccccc}
\hline & Fe & Cr & Ni & Mo & Si \\
\hline$\gamma$ & 72 & 19 & 6.7 & 1.2 & 0.9 \\
$\delta$ & 75 & 20 & 4.5 & - & - \\
P1 & 61 & 29 & 6.9 & 1.2 & 0.8 \\
P2 & 48 & 19 & 30 & 0.7 & 1.2 \\
\hline
\end{tabular}

Note: All values are \% weight.

\subsection{Scaffold Mechanical Characterization}

Figure 12 shows the stress-strain curves obtained in the compression tests, including raw data for five replicates. Four characteristic zones were observed for every fabricated scaffold: the elastic zone $(\varepsilon=0-0.05)$, yielding peak $(\varepsilon=0.05-0.20)$, stress plateau $(\varepsilon=0.20-0.40)$ and the densification zone $(\varepsilon=0.40-0.60)$. All five of the manufactured scaffolds presented a compression module between 13.03 and $13.26 \mathrm{GPa}$, a compressive stress range between 550 and $554 \mathrm{MPa}$, and a maximum compressive stress between 649 and $655 \mathrm{MPa}$. 


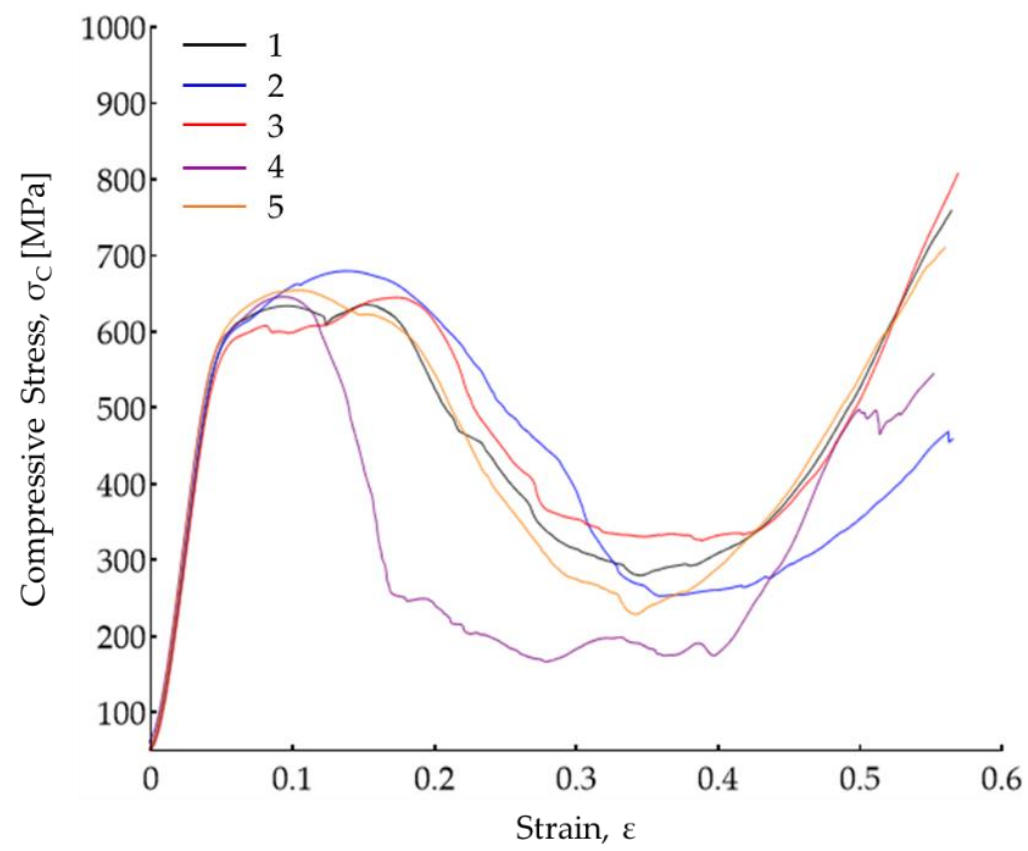

Figure 12. Compressive stress-strain curve of the compression test.

A graphic view of the compression test is shown in Figure 13. In the image corresponding to the compression test of the fifth sample (Figure 12), the yielding peak was reached between 0.1 and 0.2 of strain. Figure 13a presents the scaffold when the compression test starts. In Figure 13b, the sheets started to bend. This deformation continued in Figure 13c where some waves are observed and a warping effect on the scaffold structure. Sheets joined using micro spots started to slide between them after a strain of 0.3 , see Figure $14 \mathrm{~d}$. Afterward, images showing deformation marked as 0.4 and 0.5 (Figure 13e,f) show the scaffold collapsing until it was completely compressed.

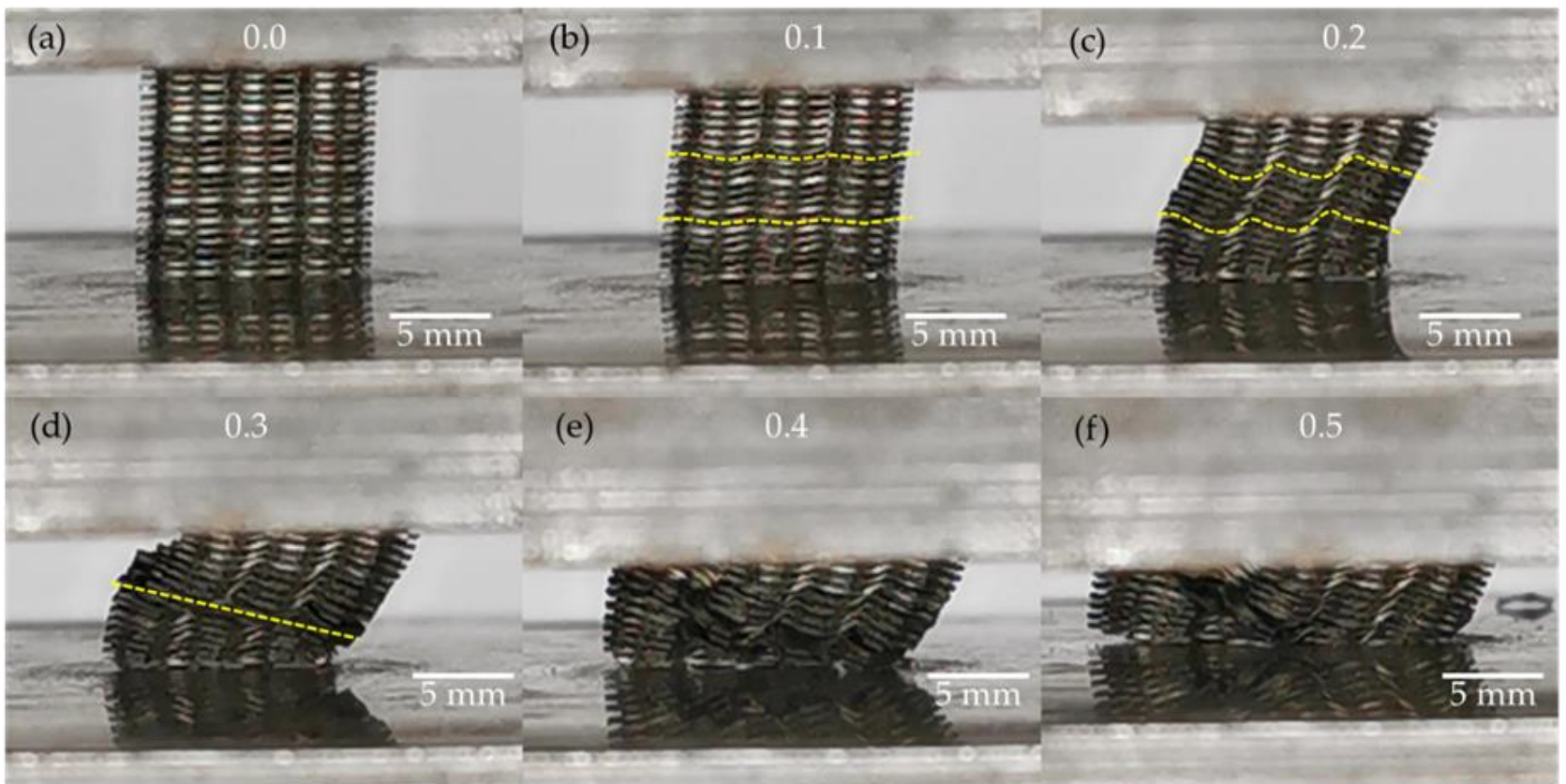

Figure 13. Compression test of the fifth sample at different strains (a) $\varepsilon=0$, (b) $\varepsilon=0.1$, (c) $\varepsilon=0.2$, (d) $\varepsilon=0.3$, (e) $\varepsilon=0.4$, and (f) $\varepsilon=0.5$. 


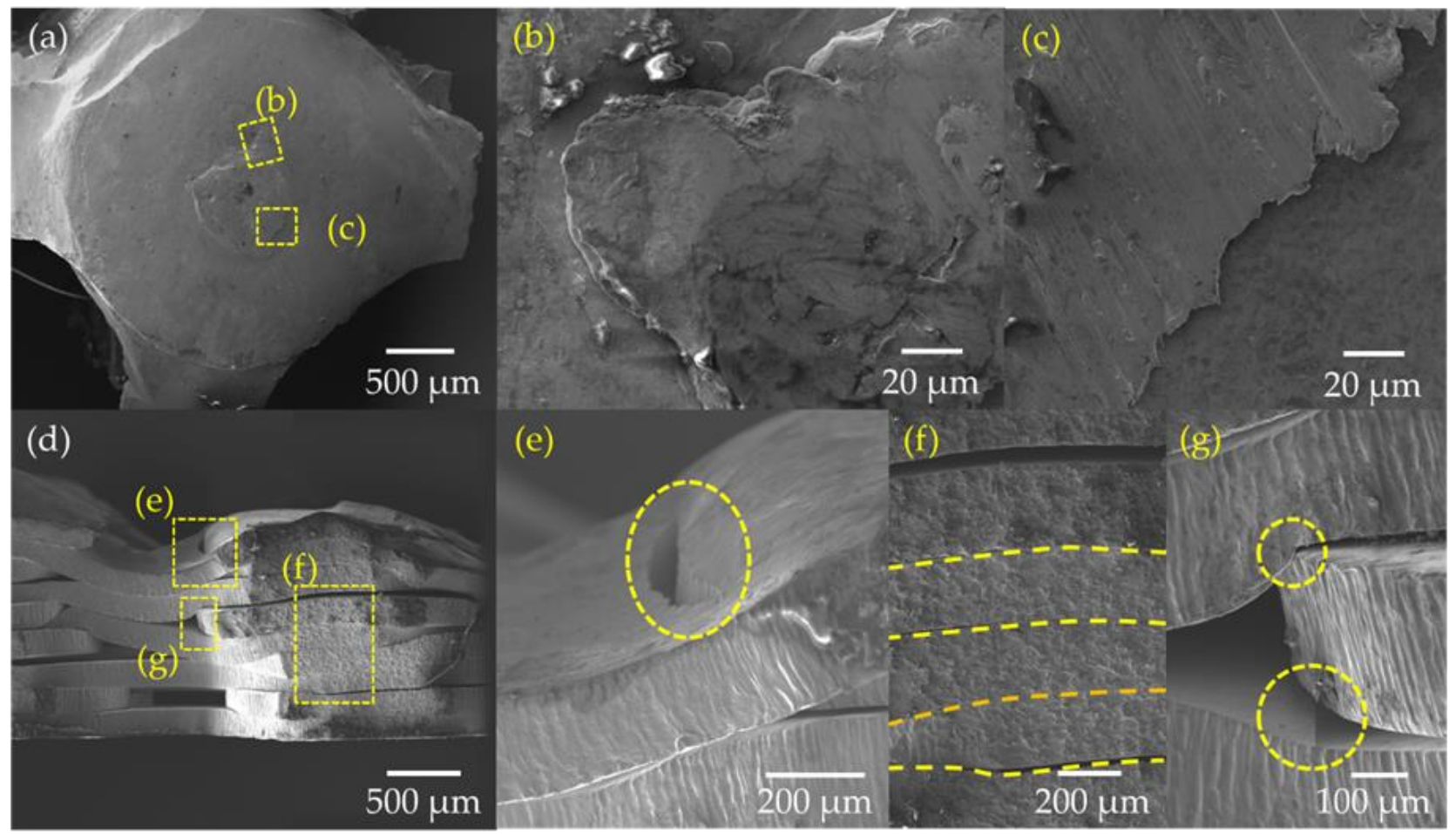

Figure 14. Fractographies of (a) micro-spot weld, (b) and (c) shear leaps of flat ductile fractures, (d) lateral view of the collapsed sheets, (e) crack due to collapse of sheets marked with a yellow circle, (f) close view of the thickness variations in the collapsed sheets, and (g) embedded zones with plastic deformation marked with yellow circles.

A fractography analysis was performed to study the scaffolding failure (Figure 14). A fractured micro-weld spot was found in Figure 14a. On the left side, plastic deformation was observed in the metal sheet as a result of the compression force between the stacked sheets. The fractured spot weld presented a shear leaps structure that indicates a flat and ductile fracture [33]; see Figure 14b. This was consistent with the slippage of the sheets that was observed during the compression test, see Figure 13c. Regarding the lateral view of the scaffold (Figure 14d), plastic deformation was observed in the sheets. This suggests that the slip between the sheets exceeds the elastic limit and causes the sheets to bend. Due to compressive loads, a crack caused by collapse was observed between the stacked sheets; see Figure 14e. It is also possible to notice a difference in the thickness of the metal sheets located in the center of the scaffold, see Figure 14f. The zones where the edges of a central sheet were embedded and produced cuts and plastic deformations in the surrounding sheets were identified with yellow circles, as shown in Figure $14 \mathrm{~g}$.

Figure 15a shows the microhardness measurement results obtained from a micro spot welding. The material's base hardness was $475 \mathrm{HV}$. Hardness is reduced in the HAZ and the fusion zone to $250 \mathrm{HV}$. This is due to the recrystallization of the product's grains to the material's fusion that takes place during laser welding. Figure $15 \mathrm{~b}$ shows results obtained from Vickers microhardness at different height points in the scaffold. Obtained values for microhardness are $400 \mathrm{HV}, 237 \mathrm{HV}$, and $215 \mathrm{HV}$ for the base material, HAZ, and fusion zone, respectively. There was no significant difference between the different heights in the scaffold. This suggests a consistency in the mechanical properties obtained in the metallic scaffold. In contrast, there was a significant variation (i.e., $p$-value $\leq 0.01$ ) between the harness in the base material, HAZ, and fusion zone. 

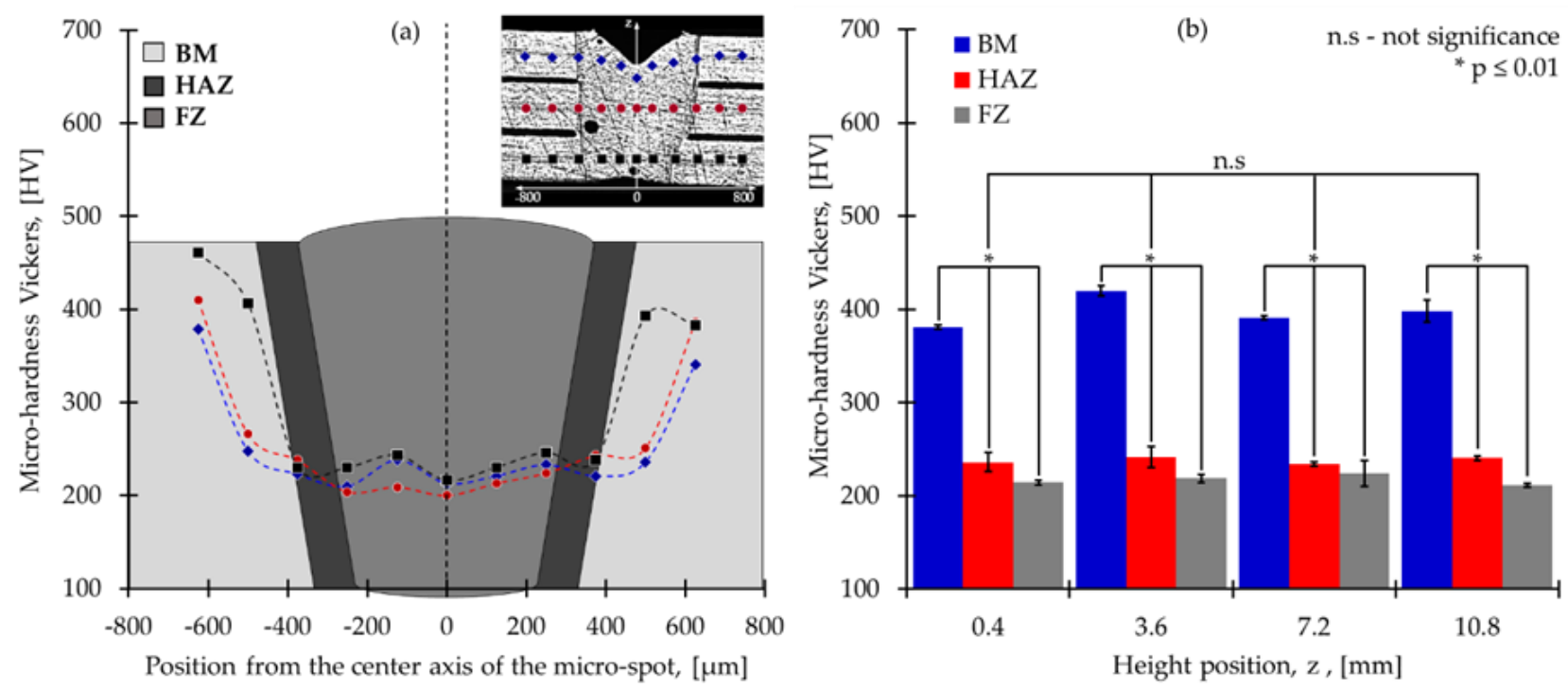

Figure 15. (a) Microhardness Vickers results in one spot and (b) microhardness results in one column of spots in all height scaffold.

\section{Discussion}

According to our results, the kerf width compensation in the laser cutting trajectories improved dimensional accuracy in the macro and micro size regimes. These results have a good agreement with the study performed by Aloke et al., which concluded that the kerf width has a major influence on the dimensional accuracy of the laser cutting process compared with thermal dilatation effects [34]. The maximum relative error found was $1.4 \%$ for all kerf width compensated samples up to $500 \mu \mathrm{m}$ in length (see Figure 4). While the maximum relative error found was $2.7 \%$ for kerf width compensated samples below $500 \mu \mathrm{m}$ of length. When medical devices such as scaffolds are manufactured, dimensional errors must be minimized in order to accomplish the bone ingrowth and to bio mimic the bone's mechanical properties $[17,18]$. Additionally, the formation of dross and slag was observed in Figure $5 \mathrm{~m}-\mathrm{p}$ ), which corresponds to samples manufactured in the micro size regimen (dimension lower than $500 \mu \mathrm{m}$ ). We attributed this phenomenon to the excessive accumulation of heat in a small area when the cutting path is performed. Further experiments must be performed to evaluate the influence of cutting paths on dimensional analysis.

AM involves promising processes for the fabrication of bone tissue-engineered porous scaffolds due to its versatility to produce complex structures. Additionally, bulk material can be processed without waste and lead-time consumption associated with traditional subtractive manufacturing methods [11]. However, limitations in the process capability are to be found, especially when the dimensional features range under $0.8 \mathrm{~mm}$ [35]. Wang et al. studied the process capability of selective laser melting (SLM) to produce porous structures with a pore size of $1000 \mu \mathrm{m}$ and strut thickness of $300 \mu \mathrm{m}$ with a maximum dimensional error of $11.7 \%$ in pore size. Their results demonstrated that powder adhesion is an inevitable effect of the process and affects the accuracy of the final pore's dimensions [36]. We reported a maximum relative error in the $X$ and $Y$ axes of $1.4 \%$ and $19.6 \%$ for a length of $1000 \mu \mathrm{m}$ for compensated and non-compensated geometries, respectively (Figure 4) for the calibration stage. While the manufactured scaffold resulted in a maximum relative error of $\sim 5 \%$ (i.e., an average height of $11.564 \mathrm{~mm}$ ) in the Z-axis due to the gaps obtained by the stacking process (Figure 7).

According to Garot et al. [4], the feedstock material cost of LPBF process is $\sim 0.1 \$ / g$ while the machine costs are between $40 \mathrm{k} \$$ and $300 \mathrm{k} \$$. LPBF processes are able to fabricate parts with a dimensional accuracy between $100 \mu \mathrm{m}$ and $300 \mu \mathrm{m}$. Additionally, a recent study by Guarino et al., compared the fabrication of a metal washer produced by SLM and by laser cutting. Their results indicated that the cost per piece was $€ 0.63$ to $€ 45.13$ for laser cutting 
and SLM, respectively. The lifecycle analysis indicated that the environmental impact of SLM is 2.5 times higher than laser cutting. Guarino concluded that laser cutting is a more economical and ecological solution when compared with SLM [37]. In the present study, the dimensional lateral accuracy $(X-Y)$ was under $\pm 5 \mu \mathrm{m}$. These results indicated higher accuracy in lateral directions (X-Y) than LPBF. For the proposed scaffold, the feedstock was 36 USD (43 sheets), the machine costs $219 \mathrm{k} \mathrm{USD}$, and the installment required space was $4 \mathrm{~m}^{3}$. Additionally, the JS-LMSW process requires fixture costs of $1 \mathrm{k} \mathrm{USD}$.

For the dimensions of the micro spots welds, the penetration depth $(\mathrm{d})$ resulted in a narrower (w) than spot width when z-height is up to $2 \mathrm{~mm}$ (Figure 9). The morphology of all the micro spot welds is like a parabolic shape due to penetration depth which is larger than the welding spot; this suggests that the micro spot welds are created in a keyhole regimen [38]. Additionally, for visual inspection (Figure 7b), there is a change of shape at the scaffold's base compared to the upper layers. It can be explained because of the less heat transferred on the Z-axis compared to the lateral $\mathrm{X}$ and $\mathrm{Y}$ axes. This effect was presented when HAZ was studied. Heat-affected zones resulted in a narrower (Figure 10b) bottom part of the spot weld compared with the lateral zone. Ventrella et al. reported a similar phenomenon in the laser seam welding; of AISI 304 metallic foils in an overlap configuration, where the heat-affected zone was wider in the top metallic foil than at the bottom. He explained that the gap between the metallic foils acted as a barrier and was the cause behind that energy dissipated in the lateral direction, which resulted in wider heat-affected zones [39]. This isolating effect was corroborated by Figure 10b, where the microstructure of the bottom sheet remained equal to the BM. This indicated that the amount of heat transferred to the bottom sheet was very low in comparison to the amount of heat transferred in the lateral directions. Additionally, some pores were observed in the fusion zone. These defects represent an area to improve the proposed process since these defects could have a negative influence on the metallic scaffold's mechanical properties [40]. The largest shrinkages were found in the center zone of the scaffold; this suggests that the concentration of heat caused by the sheet stacking and the path welding strategy increased the shrinkage.

Furthermore, the microstructure observed in the micro spot welds is a result of the primary solidification mode of ferrite to austenite (FA mode). This mode of solidification is common in austenitic stainless steels whose CrEQ/NiEQ equivalent ratio is between 1.48 and 1.95 (i.e., AISI302 has a CrEQ/NiEQ = 1.8). As the cooling rates increase, the transformation from ferrite to austenite takes on different microstructures [32]. The microstructures identified in Figure 10d occurred at high cooling rates. Besides, when the cooling rate is very high, all the ferrite is transformed, and only austenite is present. This is consistent with the microstructure observed in the micro-spot welds since in the HAZ and the border of the FZ, more structures of the vermicular and lathy ferrite type were observed. However, as we approached the center of the fusion zone, we only found an austenite phase. This indicates extremely high cooling rates in the center of the weld due to the laser welding process. The EDS analysis indicates a higher concentration of precipitates in the HAZ; this occurs when the material is heated close to the solidus temperature, which causes supersaturation of the austenite matrix [32]. Additionally, HAZ showed a hardness of $237 \mathrm{HV}$, greater than the hardness of $215 \mathrm{HV}$ presented in the fusion zone (see Figure 14a). These results suggest that the supersaturation of precipitates produced a hardening effect in the HAZ zone. Additionally, the base material did not present a grain thickening close to the HAZ; this is a common behavior in materials that come from cold work. However, due to the recrystallization of the material and due to the melting at the spot weld, softening occurred in the HAZ and fusion zones presenting lower values of hardness than the base material. Solati et al. [41] reported a reduction in the hardness results from the BM forward to the center of the FZ due to changes in microstructure in laser seam welds of AISI316L sheet of $0.6 \mathrm{~mm}$ of thickness. The microstructure observed in this study has also been observed in other stainless steels (i.e., AISI304, AISI316) seam welded by an Nd-YAG laser [42]. 
According to the bone mechanical properties found in literature listed in Table 5, the compression module obtained in the created scaffolds using the proposed methodology behaves similarly to that of the cortical bone, with a higher compressive yield and maximum stress [43]. These results prove that the developed scaffolds offer a wide safety window towards the stress shielding effect. While exceeding the mechanical properties of bone tissue, the unique architecture (porosity and morphology) provides a wide surface area for osteoblast migration, proliferation, and ultimately, surface and inner mineralization leading to full integration of the implant $[44,45]$. Further research will be performed to improve the scaffold's design as well as to increase the porosity level to achieve a higher degree of resemblance to the mechanical properties like cortical bone. Another parameter that should be taken into consideration is the elastic modulus, which should behave similarly to that of the bone in order to ensure adequate load transfer, which has been widely studied in dental implants [46,47]. Additionally, further experiments must be centered in the application, specifically in vitro and in vivo tests. LPBF processes have demonstrated their capacity to manufacture medical applications with good results in clinical studies. For example, Pobloth et al. [48] reported the treatment of critical segmental bone defects in 19 patients with 3d-Ti mesh scaffolds fabricated by laser sintering. Radiographic analysis showed bone defect bridging in most of the cases after 28 months after implantation. However, according to Garot et al. [4], scaffold fabricated with AM techniques must be optimized to obtain an architecture with good mechanical and biological properties and implants tested clinically.

Table 5. Mechanical properties in compression of the human cortical bone and the fabricated scaffold.

\begin{tabular}{cccc}
\hline & [15] & [13] & This Study \\
\hline Material & Natural bone & AISI316L & AISI302 \\
Measured porosity (\%) & $3-12$ & $40-50$ & $46-47$ \\
Compressive modulus (GPa) & $14-28$ & $26-46$ & $13.03-13.26$ \\
Yielding stress (MPa) & $120-175$ & - & $550-554$ \\
Ultimate strength (MPa) & $190-245$ & $21-32$ & $649-655$ \\
Fabrication method & - & SLS & JS-LMSW
\end{tabular}

JS-LMSW allowed obtaining joined metallic sheets with the desired pore shape, size, and distribution. In comparison to the LPBF processes, JS-LMSW represents a smaller number of trajectories performed by the laser beam to obtain the same porous volume. Furthermore, joining the sheets by a matrix of discrete micro spot welds leads to a lower amount of energy used than the energy required for the fusion of the entire section and less heat dissipation which results in less probability of warping effects compared with LPBF [2]. Furthermore, the compression tests demonstrated that the LMSW avoids the inconsistent mechanical properties caused by no uniform heat dissipation [2] or porosities due to partial fusion [4], which are commonly presented in LPBF. In our study, the measured porosity resulted similarly to designed porosity (i.e., a relative error between $0.5 \%$ and $1.1 \%$ ). The use of metallic sheets as feedstock eliminates the problems related to the removal of the entrapped powder and material wastage presented in LPBF [2]. However, further experiments must be performed to evaluate the presence of porosities and shrinkages in the spot weld as a way to avoid them and their effect on mechanical testing. The potential solutions are to change the shielding gas to N2, to reduce the free spaces between stacked sheets modifying the fixture, and to evaluate other values of laser intensity through the laser beam defocusing $[49,50]$.

\section{Conclusions}

The novel fabrication of austenitic stainless steel scaffolds for bone tissue engineering applications was successfully achieved. The sheet lamination AM proposed methodology showed high consistency and a promising future in the tissue engineering field. This study drew the following conclusions: 
- $\quad$ After the calibration study, the accuracy of the laser micro-cutting was $1.4 \%$ for all kerf width compensated samples of up to $500 \mu \mathrm{m}$ (macro-shapes) of length and $2.7 \%$ for kerf width compensated samples below $500 \mu \mathrm{m}$ (micro-shapes) of length. This indicated the capability of the methodology to produce geometries in the micro size regimen with high repeatability;

- The micro-spot welds presented a penetration depth between 704 and $736 \mu \mathrm{m}$, a width between 584 and $616 \mu \mathrm{m}$, and a HAZ between 25 and $34 \mu \mathrm{m}$. Shrinkages and pores were identified as the principal defects to mitigate in future investigations;

- The microstructures of vermicular and lathy ferrite observed in the FZ and HAZ regions of the spot welds indicated high cooling rates during the laser welding process. Additionally, these high cooling rates caused a supersaturation of precipitates in the HAZ regions. The high cooling rates and the gaps observed between sheets are probably the main cause of the shrinkage defects in the micro-spot welds;

- The fabricated scaffolds presented a compressive modulus between 13.03 GPa and 13.26 GPa. which are close to the cortical bone properties. Additionally, the scaffolds showed a measured porosity between $46 \%-47 \%$, which is in good agreement with the conceptual design;

- The main reason for the failure of the scaffolds at compression tests was the sliding of the AISI302 sheets. This phenomenon occurs between the 0.1 and 0.2 strain deformation. The sliding of the sheets causes bending deformations, and the collapse initiates shearing cracks in the interfaces of the sheets;

- The microhardness obtained was $400 \mathrm{HV}, 237 \mathrm{HV}$, and $215 \mathrm{HV}$ for the base material, $\mathrm{HAZ}$, and fusion zone, respectively. The recrystallization of the material due to the melting of the material caused a softening effect in the FZ and HAZ regions. The supersaturation precipitates caused a hardening effect in the HAZ region in comparison with the FZ. No significant difference was found between the microhardness measurement along with different height positions of the scaffold.

Author Contributions: E.G.-L. and E.V.; methodology, E.G.-L., E.V. and L.D.C.-V.; validation, L.D.C.V.; formal analysis, E.G.-L. and L.D.C.-V.; investigation, E.G.-L., E.V., L.D.C.-V., V.S.-I. and C.A.R.; resources, C.A.R. and E.G.-L.; data curation, E.G.-L., E.V., L.D.C.-V., V.S.-I. and C.A.R.; writingoriginal draft preparation, E.G.-L. and L.D.C.-V. Article writing, E.G.-L., E.V., L.D.C.-V., V.S.-I. and C.A.R.; project administration, E.G.-L. and E.V.; funding acquisition, C.A.R. All authors have read and agreed to the published version of the manuscript.

Funding: This work was funded by the Tecnologico de Monterrey through the Research Group in Advanced Manufacturing and CONACyT (Grant 662531).

Acknowledgments: The authors would like to thank the assistance received from Regina Elizabeth Vargas Mejia and Gabriel Soto Urzua from the Tecnologico de Monterrey. We also want to express our gratitude to Carlos Antonio Santana Delgado from The Autonomous University of Nuevo Leon (UANL). This work has been supported by the Advanced Manufacturing Focus Group of Tecnologico de Monterrey.

Conflicts of Interest: The authors declare no conflict of interest with respect to the research, authorship, and/or publication of this article.

\section{References}

1. Chen, Y.; Li, W.; Zhang, C.; Wu, Z.; Liu, J. Recent Developments of Biomaterials for Additive Manufacturing of Bone Scaffolds. Adv. Healthc. Mater. 2020, 9, 2000724. [CrossRef]

2. Bahraminasab, M. Challenges on Optimization of 3D-Printed Bone Scaffolds. BioMed. Eng. Online 2020, 19, 69. [CrossRef]

3. Chocholata, P.; Kulda, V.; Babuska, V. Fabrication of Scaffolds for Bone-Tissue Regeneration. Materials 2019, 12, 568. [CrossRef]

4. Garot, C.; Bettega, G.; Picart, C. Additive Manufacturing of Material Scaffolds for Bone Regeneration: Toward Application in the Clinics. Adv. Funct. Mater. 2021, 31, 2006967. [CrossRef]

5. Daga, B.; Rivera, G.; Boeri, R. Review of the Regulations for the Use of Stainless Steels for Orthopedic Implants in Argentina. J. Phys. Conf. Ser. 2007, 90, 012045. [CrossRef]

6. Majumdar, J.D.; Kumar, A.; Pityana, S.; Manna, I. Laser Surface Melting of AISI 316L Stainless Steel for Bio-Implant Application. Proc. Natl. Acad. Sci. India Sect. A Phys. Sci. 2018, 88, 387-403. [CrossRef] 
7. Lietaert, K.; Wauthle, R.; Schrooten, J. Porous Metals in Orthopedics. In Biomaterials in Clinical Practice; Springer: Cham, Switzerland, 2017; pp. 281-301.

8. Ortiz, A.J.; Fernández, E.; Vicente, A.; Calvo, J.L.; Ortiz, C. Metallic Ions Released from Stainless Steel, Nickel-Free, and Titanium Orthodontic Alloys: Toxicity and DNA Damage. Am. J. Orthod. Dentofac. Orthop. 2011, 140, 115-122. [CrossRef]

9. Grygier, D.; Hoppe, V.; Ziety, A.; Rutkowka-Gorczyca, M. Evaluation of Differentiation of Structural and Physico-Chemical Properties of Orthodontic Wires of AISI304 Stainless Steel. Eng. Biomater. 2018, 146, 8-13.

10. Cedeño-Viveros, L.D.; Vázquez-Lepe, E.; Rodríguez, C.A.; García-López, E. Influence of Process Parameters for Sheet Lamination Based on Laser Micro-Spot Welding of Austenitic Stainless Steel Sheets for Bone Tissue Applications. Int. J. Adv. Manuf. Technol. 2021, 115, 247-262. [CrossRef]

11. Tan, X.P.; Tan, Y.J.; Chow, C.S.L.; Tor, S.B.; Yeong, W.Y. Metallic Powder-Bed Based 3D Printing of Cellular Scaffolds for Orthopaedic Implants: A State-of-the-Art Review on Manufacturing, Topological Design, Mechanical Properties and Biocompatibility. Mater. Sci. Eng. C 2017, 76, 1328-1343. [CrossRef]

12. Hing, K.A. Bone Repair in the Twenty-First Century: Biology, Chemistry or Engineering? Philos. Trans. R. Soc. A Math. Phys. Eng. Sci. 2004, 362, 2821-2850. [CrossRef]

13. Dewidar, M.M.; Khalil, K.A.; Lim, J.K. Processing and Mechanical Properties of Porous 3 16L Stainless Steel for Biomedical Applications. Trans. Nonferrous Met. Soc. China 2007, 17, 468-473. [CrossRef]

14. Xie, F.; He, X.; Cao, S.; Qu, X. Structural and Mechanical Characteristics of Porous 316L Stainless Steel Fabricated by Indirect Selective Laser Sintering. J. Mater. Process. Tech. 2013, 213, 838-843. [CrossRef]

15. Čapek, J.; Vojtěch, D. Properties of Porous Magnesium Prepared by Powder Metallurgy. Mater. Sci. Eng. C 2013, 33, 564-569. [CrossRef]

16. Vangapally, S.; Agarwal, K.; Sheldon, A.; Cai, S. Effect of Lattice Design and Process Parameters on Dimensional and Mechanical Properties of Binder Jet Additively Manufactured Stainless Steel 316 for Bone Scaffolds. Procedia Manuf. 2017, 10, 750-759. [CrossRef]

17. Wu, S.; Liu, X.; Yeung, K.W.K.; Liu, C.; Yang, X. Biomimetic Porous Scaffolds for Bone Tissue Engineering. Mater. Sci. Eng. R 2014, 80, 1-36. [CrossRef]

18. Alvarez, K.; Nakajima, H. Metallic Scaffolds for Bone Regeneration. Materials 2009, 2, 790-832. [CrossRef]

19. ASM International. Additive Manufacturing Processes; ASM International: Novelty, OH, USA, 2020; Volume 24, ISBN 978-1-62708288-4.

20. Xu, B.; Wu, X.Y.; Lei, J.G.; Cheng, R.; Ruan, S.C.; Wang, Z.L. Laminated Fabrication of 3D Micro-Electrode Based on WEDM and Thermal Diffusion Welding. J. Mater. Process. Technol. 2015, 221, 56-65. [CrossRef]

21. Xu, B.; Wu, X.; Luo, F.; Du, C.; Sun, X. Research on the Forming Mechanism of Micro-Moulds Based on Laminated Slip-Welding of Ultrathin Stainless Steel Foils. Adv. Mater. Res. 2011, 314-316, 1818-1822. [CrossRef]

22. Zhong, J.M.; Wu, X.Y.; Xu, B.; Li, J.B.; Luo, F.; Cheng, R.; Ruan, S.C. Laminated Fabrication of Micro-Stepped Gear Mold Based on WEDM and Thermal Diffusion Welding. Int. J. Adv. Manuf. Technol. 2015, 78, 1233-1240. [CrossRef]

23. Xu, B.; Wu, X.Y.; Ling, S.Q.; Luo, F.; Du, C.L.; Sun, X.Q. Fabrication of 3D Metal Micro-Mold Based on Femtosecond Laser Cutting and Micro-Electric Resistance Slip Welding. Int. J. Adv. Manuf. Technol. 2013, 66, 601-609. [CrossRef]

24. Kleine, K.F.; Whitney, B.; Watkins, K.G. Use of Fiber Lasers for Micro Cutting Applications in the Medical Device Industry. In Proceedings of the ICALEO 2002-21st International Congress on Applications of Laser and Electro-Optics, Scottsdale, AZ, USA, 14-17 October 2002.

25. Narayan, R.; Goering, P. Guest Editors Laser Micro-and Nano Fabrication of Biomaterials. Mater. Res. Soc. Bull. 2011, 36, 973-982. [CrossRef]

26. Xie, J. Laser Hermetic Welding of Implantable Medical Devices. In Joining and Assembly of Medical Materials and Devices; Woodhead Publishing Limited: Sawston, UK, 2013; pp. 211-235, ISBN 9781845695774.

27. Quintino, L. Introduction to Joining Methods in Medical Applications. In Joining and Assembly of Medical Materials and Devices; Woodhead Publishing Limited: Sawston, UK, 2013; pp. 28-46, ISBN 9781845695774.

28. Pequegnat, A.; Zhou, Y. Joining of Platinum (Pt) Alloy Wires to Stainless Steel Wires for Electronic Medical Devices. In Joining and Assembly of Medical Materials and Devices; Woodhead Publishing Limited: Sawston, UK, 2013; pp. 154-177, ISBN 9781845695774.

29. Murakawa, H. Residual Stress and Distortion in Laser Welding. Handb. Laser Weld. Technol. 2013, 2, 374-398. [CrossRef]

30. Patschger, A.; Bliedtner, J.; Bergmann, J.P. Approaches to Increase Process Efficiency in Laser Micro Welding. Phys. Procedia 2013, 41, 592-602. [CrossRef]

31. Franco, A.; Romoli, L.; Musacchio, A. Modelling for Predicting Seam Geometry in Laser Beam Welding of Stainless Steel. Int. J. Therm. Sci. 2014, 79, 194-205. [CrossRef]

32. Lippold, J.; Kotecki, D. Welding Metallurgy and Weldability of Stainless Steel; John Wiley \& Sons: Milan, MI, USA, 2006 ; Volume 21.

33. Aliya, D.; Becker, W.T.; Shipley, R. Failure Analysis and Prevention; ASM International: Novelty, OH, USA, 2018.

34. Aloke, R.; Girish, V.; Scrutton, R.F.; Molian, P.A. A Model for Prediction of Dimensional Tolerances of Laser Cut Holes in Mild Steel Thin Plates. Int. J. Math. Tools Manuf. 1997, 37, 1069-1078. [CrossRef]

35. Calignano, F.; Lorusso, M.; Pakkanen, J.; Trevisan, F.; Ambrosio, E.P.; Manfredi, D.; Fino, P. Investigation of Accuracy and Dimensional Limits of Part Produced in Aluminum Alloy by Selective Laser Melting. Int. J. Adv. Manuf. Technol. 2017, 88, 451-458. [CrossRef] 
36. Wang, D.; Yang, Y.; Liu, R.; Xiao, D.; Sun, J. Study on the Designing Rules and Processability of Porous Structure Based on Selective Laser Melting (SLM). J. Mater. Process. Technol. 2013, 213, 1734-1742. [CrossRef]

37. Guarino, S.; Ponticelli, G.S.; Venettacci, S. Enviromental Assessment of Selective Laser Melting Comparer with Laser Cutting of 316L Stainless Steel: A Case Study for Flat Washers' Production. CIRP J. Manuf. Sci. Technol. 2020, 31, 525-538. [CrossRef]

38. Krasnoperov, M.Y.; Pieters, R.R.G.M.; Richardson, I.M. Weld Pool Geometry during Keyhole Laser Welding of Thin Steel Sheets. Sci. Technol. Weld. Join. 2004, 9, 501-506. [CrossRef]

39. Ventrella, V.A.; Berretta, J.R.; de Rossi, W. Pulsed Nd:YAG Laser Seam Welding of AISI 316L Stainless Steel Thin Foils. J. Mater. Process. Technol. 2010, 210, 1838-1843. [CrossRef]

40. Katayama, S. Defect Formation Mechanisms and Preventive Procedures in Laser Welding. In Handbook of Laser Welding Technologies; Woodhead Publishing Limited: Sawston, UK, 2013; pp. 332-373, ISBN 9780857098771.

41. Solati, A.; Bani Mostafa Arab, N.; Mohammadi-Ahmar, A.; Fazli Shahri, H.R. Multi-Criteria Optimization of Weld Bead in Pulsed Nd:YAG Laser Welding of Stainless Steel 316. Proc. Inst. Mech. Eng. Part E J. Process. Mech. Eng. 2019, 233, 151-164. [CrossRef]

42. Kumar, N.; Mukherjee, M.; Bandyopadhyay, A. Comparative Study of Pulsed Nd:YAG Laser Welding of AISI 304 and AISI 316 Stainless Steels. Opt. Laser Technol. 2017, 88, 24-39. [CrossRef]

43. Morgan, E.F.; Unnikrisnan, G.U.; Hussein, A.I. Bone Mechanical Properties in Healthy and Diseased States. Annu. Rev. Biomed. Eng. 2018, 20, 119-143. [CrossRef]

44. Borcherding, K.; Schmidmaier, G.; Hofmann, G.O.; Wildemann, B. The Rationale behind Implant Coatings to Promote Osteointegration, Bone Healing or Regeneration. Injury 2021, 52, S106-S111. [CrossRef]

45. Frosch, K.-H.; Barvencik, F.; Lohmann, C.H.; Viereck, V.; Siggelkow, H.; Breme, J.; Dresing, K.; Stürmer, K.M.; Frosch, H.K. Migration, Matrix Production and Lamellar Bone Formation of Human Osteoblast-Like Cells in Porous Titanium Implants. Cells Tissues Organs 2002, 170, 214-227. [CrossRef]

46. Pérez-Pevida, E.; Brizuela-Velasco, A.; Chávarri-Prado, D.; Jiménez-Garrudo, A.; Sánchez-Lasheras, F.; Solaberrieta-Méndez, E.; Diéguez-Pereira, M.; Fernández-González, F.J.; Dehesa-Ibarra, B.; Monticelli, F. Biomechanical Consequences of the Elastic Properties of Dental Implant Alloys on the Supporting Bone: Finite Element Analysis. BioMed Res. Int. 2016, 2016. [CrossRef]

47. Brizuela, A.; Herrero-Climent, M.; Rios-Carrasco, E.; Rios-Santos, J.V.; Pérez, R.A.; Manero, J.M.; Mur, J.G. Influence of the Elastic Modulus on the Osseointegration of Dental Implants. Materials 2019, 12, 980. [CrossRef]

48. Pobloth, A.M.; Checa, S.; Razi, H.; Petersen, A.; Weaver, J.C.; Chmidt-Bleek, K.; Windolf, M.; Tatai, A.A.; Roth, C.P.; Schaser, K.D.; et al. Mechanobiologically Optimized 3D Titanium-Mesh Scaffolds Enhance Bone Regeneration in Critical Segmental Defects in Sheep. Sci. Transl. Med. 2018, 10. [CrossRef] [PubMed]

49. Sun, J.; Nie, P.; Feng, K.; Li, Z.; Guo, B.; Jiang, E. The Elimination of Pores in Laser Welds of AISI 304 Plate Using Different Shielding Gases. J. Mater. Process. Technol. 2017, 248, 56-63. [CrossRef]

50. Hong, K.M.; Shin, Y.C. The Effects of Interface Gap on Weld Strength during Overlapping Fiber Laser Welding of AISI 304 Stainless Steel and AZ31 Magnesium Alloys. Int. J. Adv. Manuf. Technol. 2017, 90, 3685-3696. [CrossRef] 